\title{
Antibody-drug conjugates: integrated bioanalytical and biodisposition assessments in lead optimization and selection
}

\author{
Maribel Beaumont ${ }^{1}$, Daniela Tomazela ${ }^{1}$, Douglas Hodges², Grigori Ermakov', Edward Hsieh ${ }^{1}$, Isabel Figueroa², \\ On-Yee So ${ }^{2}$, Yaoli Song ${ }^{2}$, Huiping Ma², Svetlana Antonenko², Wondwessen Mengesha², Yi Wei Zhang², \\ Shuli Zhang ${ }^{1}$, SuChun Hseih ${ }^{1}$, Gulesi Ayanoglu', Xiaoyan Du', Eric Rimmer ${ }^{1}$, Michael Judo ${ }^{1}$, Franklin Vives ${ }^{1}$, \\ Jennifer H. Yearley ${ }^{3}$, Christina Moon ${ }^{3}$, Anthony Manibusan ${ }^{4}$, Nick Knudsen ${ }^{4}$, Andy Beck ${ }^{4}$, Damien Bresson ${ }^{4}$, \\ Dennis Gately ${ }^{4}$, Divas Neupane ${ }^{2}$ and Enrique Escandón ${ }^{2^{*}}$ (D)
}

\begin{abstract}
Therapies based on monoclonal antibodies (mAbs) have delivered an impressive success in the clinics due to their exquisite specificity, potential for agonistic or antagonistic responses, tunable effector function, and optimal pharmacokinetic properties. Building on these inherent antibody properties, the design and development of antibody-drug conjugates (ADCs) with improved or gained therapeutic activity and safety has been successfully demonstrated in oncological applications. There is enormous potential for this new type of hybrid biologics but there are also significant engineering, manufacturing and bioanalytical challenges. In this manuscript, we highlight the range and diversity of assays that are critical to characterize the individual components of ADCs-linker, carrier, and payload. We discuss a series of in vitro and in vivo preclinical experimental approaches we implemented to characterize two anti-inflammatory steroid bearing ADCs, and an ADC bearing a modified glucagon-like peptide 1 receptor/glucagon receptor co-agonist peptide.
\end{abstract}

Keywords: Antibody-drug conjugates, Immunoassay, LC-MS, Biodisposition, CD74, CD25, GLP1R, GCGR

\section{Background}

Antibodies and antibody-based molecules constitute one of the most efficacious classes of therapeutic products in the biotechnology industry. Due to their generally long half-life and specificity encoded in discrete complementary determining regions, it was originally believed that, in addition to an excellent therapeutic window, the pharmacokinetic properties of recombinant antibodies will be both similar and predictable. However, it is now well understood that many factors, depending on the specific antibody and intended target, may significantly affect the drug pharmacokinetic behavior (Tabrizi et al., 2006).

\footnotetext{
* Correspondence: Enrique.escandon@merck.com

${ }^{2}$ Biologics DMPK and Disposition, MRL, Merck \& Co., Inc., 901 S. California

Avenue, Palo Alto, CA 94304-1104, USA

Full list of author information is available at the end of the article
}

Antibody-drug conjugates represent a new kind of therapeutic agents which are gaining importance especially in the oncology field (Sievers and Senter, 2013). They are the product of covalently linking a monoclonal antibody with a small molecule or peptide drug (payload). Typically, the mAb will enable a targeted delivery of the payload to a defined cell population of choice. The increase in total mass of ADC compared to payload alone improves the payload exposure due to diminished renal uptake and clearance of $\mathrm{ADC}$. In addition, $\mathrm{ADCs}$ are expected to retain binding to the neonatal Fc receptor $(\mathrm{FcRn})$, which is responsible for salvaging both immunoglobulin G (IgG) and albumin from cellular catabolism in a pH-dependent recycling and transcytosis mechanism (Andersen and Sandlie, 2009; Roopenian and Akilesh, 2007). 
For ADCs with a targeted intracellular payload, the challenge is to successfully design ADCs with a balanced chemical linker strong enough to be stable in blood while efficiently cleaved once inside the cell lysosomal compartment to release its active payload. These properties would reduce systemic pharmacological exposure and non-specific effects associated with the free drug. Alternatively, for extracellular targets the mAb portion can serve as a carrier to extend the half-life of the payload from minutes to days and systemic exposure by several folds compared to when dosed as a small molecule drug. In this scenario it is critical that the stability of the linker and payload in the circulation are engineered to match appropriately the expected increase in exposure and half-life of the immunoconjugate. This is of particular importance for peptide payloads as they are more likely to be targeted by enzymatic catabolism in the systemic circulation.

Generally, conjugation of the drug to the antibody has been achieved through lysine or existing cysteine residues resulting in heterogeneous conjugations (Casi and Neri, 2012). However, there is a tremendous interest and research to produce more homogeneous ADCs through site specific conjugations using either engineered cysteine residues (Junutula et al., 2010) or through the site-specific incorporation of non-natural amino acids with unique reactive groups while minimizing antibody scaffold modifications (Axup et al., 2012; Kern et al., 2016b; Tian et al., 2014; Zimmerman et al., 2014). Regardless of the methods used for generating ADCs, a thorough characterization of the effects that the conjugated products and procedures may have on the functional properties of the antibody moiety itself is critical for lead selection and development; including binding properties, affinity and specificity, Fc effector function, off-target disposition, aggregation and novel protein interactions. In addition, because of their multi-component nature (mAb, linker and payload), these hybrid entities are more complex than a "simple" $\mathrm{mAb}$ or separate payload. For any given combination of $\mathrm{mAb}$, linker, payload, site, type of conjugation, and the achieved drug-antibody ratio (DAR), the resulting products will consist of a mixture of ADC variants with different physico-chemical properties. This in turn, depending on the resulting heterogeneity, may affect its stability, pharmacokinetics and disposition, adversely changing the overall ADC safety and efficacy profile. Therefore, each experimental conjugate requires the development of a combination of various analytical procedures for a thorough physico-chemical monitoring, from antibody and payload conjugation, immunoassay, and cell based procedures to standard and innovative fit-for-purpose LC-MS methods. There are excellent reviews that cover several aspects of this process(Perez et al., 2014). Descriptions of bioanalytical techniques have been recently published (Gorovits et al., 2013; Kaur et al., 2013; Wakankar et al., 2011). In this manuscript, we describe several specific experimental examples of different site-specific conjugated ADC case-studies in order to highlight the complexity and range of bioanalytical methods required to characterize their properties in vitro and their pharmacokinetic and disposition behavior in vivo (Outlined in Fig. 1). Two cases presented here are: 1) Anti-inflammatory steroid-ADCs directed to specific cell surface receptors (CD25 and CD74) for targeted internalization; 2) A modified Glucagon-like Peptide 1 receptor/Glucagon receptor (GLP1R/GCGR) co-agonist-bearing ADC (Pep-ADC) designed for improved systemic exposure and prolonged pharmacological activity via peptide cell surface receptor binding and activation.

\section{Methods}

All animal procedures described here were performed in accordance with the established guidelines and regulations by our Institutional Animal Care and Use Committee (IACUC). Animals were housed and maintained in facilities under a protocol approved by and in accordance with the guidelines of the American Association for Assessment and Accreditation of Laboratory Animal Care.

\section{Monoclonal antibodies and ADC compounds}

Monoclonal rat-mouse chimeric anti- mouse IL-2R $\alpha$ (CD25) IgG1 was coupled to dexamethasone (Dex) with either a novel proprietary phosphate based linker (anti-CD25-Phos-Dex) (Kern et al., 2016a) or with a cathepsin based linker (anti-CD25-Cat-Dex) (Kern et al., 2016b), as described in the respective references. These ADCs were generated in partnership with Ambrx Inc. (La Jolla, CA). Humanized anti-human CD74 IgG1 either unconjugated (unconjugated anti-CD74) or conjugated to budesonide using phosphate linker (anti-CD74-Phos-Bud), humanized anti-human CD74 IgG4 (anti-CD74-011), human anti-viral IgG4 (mAb3), and mAb3 conjugated to modified Glucagon-like Peptide 1 receptor/Glucagon receptor (GLP1R/GCGR) co-agonist peptide (Pep-ADC), were all generated in partnership with Ambrx. Mouse anti-Dexamethasone IgG1 (MEB113.53F3.104A) and mouse anti-Dexamethasone IgG2a (MEB113.8D1.7F) were generated at Merck \& Co., Inc. (MRL, Palo Alto, CA).

\section{In vitro stability of anti-CD25-Phos-Dex and anti- CD25- Cat-Dex}

Anti -CD25-Phos-Dex or anti-CD25-Cat-Dex (15 $\mu \mathrm{g} /$ $150 \mu \mathrm{L}$ plasma) was spiked in normal male DBA1 mouse plasma for up to 18 days at $37{ }^{\circ} \mathrm{C}$. After incubation, samples at selected time points were analyzed by total 


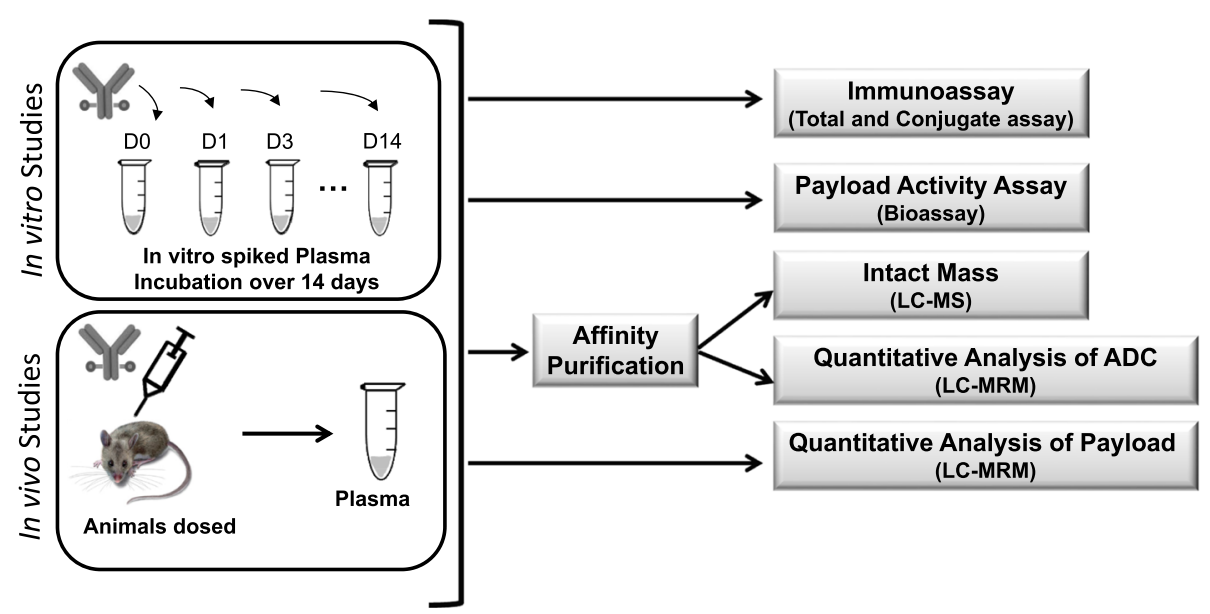

Fig. 1 Schematic illustrating the range of bioanalytical methods used in the studies described in this paper. These methods can be applied to understand concentration, activity, and intactness of antibody-drug conjugates in vitro and in vivo

antibody immunoassay (Total IA), measuring anti-CD25 antibody still capable of binding the target regardless of the presence or absence of payload, and ADC specific immunoassay (ADC IA) using Mesoscale Discovery (MSD) sandwich immunoassay (Meso Scale Discovery, Rockville, MD), and free dexamethasone was determined by LC-MS (Free Dex). For Total IA, the plasma samples spiked with each ADC were added to MSD MA6000 96-Small Spot plate coated with recombinant mouse IL-2 R $\alpha$ (R\&D System, Minneapolis, MN) as a capture molecule. After incubation and washes, wells were incubated in goat anti-rat IgG (Fc), F (ab')2-Biotin (Sigma-Aldrich, St. Louis, MO). Finally for detection, SULTO-TAG labeled Streptavidin was added to the wells, signal was read on the MESO SECTOR S 600 reader after adding MSD read Buffer T. For Anti-CD25 conjugate ADC specific immunoassay, similar procedure was followed, however, mouse anti-dexamethasone IgG2a (MEB113.8D1.7F)-Biotin (Merck) was used to detect dexamethasone containing intact $\mathrm{ADC}$ in spiked plasma.

For LC-MS detection of Dexamethasone, plasma protein was precipitated by addition of $400 \mu \mathrm{L}$ of internal standard solution, consisting of $20 \mathrm{ng} / \mathrm{mL}$ of Dexamethasone-d4 (TLC PharmaChem, Vaughan, ON) in acetonitrile to $40 \mu \mathrm{L}$ of plasma. Samples were vortexed for $30 \mathrm{~s}$ and centrifuged at 14,000 rpm for $10 \mathrm{~min}$ at $4{ }^{\circ} \mathrm{C}$. Supernatants were transferred to a clean tube and dried in Centrivap vacuum concentrator (Labconco, Kansas City, MO). Samples were reconstituted with $40 \mu \mathrm{L}$ of $50 \%$ methanol /aqueous solution and $5 \mu \mathrm{L}$ was injected into the ESI(-)LC-MS/MS (Acquity Waters, Milford, MA; TSQ Vantagem, ThermoScientific, Waltham MA). Analysis was performed on a Ascentis Express $\mathrm{C} 18(50 \mathrm{~mm} \times 3 \mathrm{~mm} \times 2.7 \mu \mathrm{m})$ (Sigma-Aldrich) column with a 3 min linear gradient from 50 to $95 \%$
Buffer B (Buffer A: 0.1\% formic acid aqueous solution; Buffer B: $0.1 \%$ formic acid in acetonitrile) at $0.4 \mathrm{~mL} / \mathrm{min}$. Dexamethasone and dexamethasone- $\mathrm{d} 4$ were detected using the transitions $437.0>361.3$, and $441.0>363.3$, respectively. Method showed linearity from $0.1 \mathrm{ng} / \mathrm{mL}$ to $2000 \mathrm{ng} / \mathrm{mL}$.

\section{In vivo stability of anti-CD74-Phos-Bud in human CD74 transgenic mice}

Human CD74 expressing transgenic (Tg) mice (B6.Cg- $\operatorname{Tg}(\mathrm{CD} 74) \mathrm{AR} 194 \mathrm{Ayr} / \mathrm{j})$ were generated and characterized previously (Honey et al., 2004). These Tg mice ( $n=2$ /group) were dosed intravenously (IV) with either 3,10 or $30 \mathrm{mg} / \mathrm{kg}$ of anti-CD74-Phos-Bud and plasma samples were collected at designated time points. Samples were subjected to MSD immunoassays. For total anti-CD74 immunoassay (Total IA), measuring anti-CD74 antibody still capable of binding the target regardless of the presence or absence of payload, recombinant human CD74 (R\&D System) was plated on MSD MA6000 96-Small Spot plate as a target capture and mouse anti-human IgG-SULTO-TAG (SouthernBiotech, Birmingham, AL) was used as detection reagent. For anti-CD74-Phos-Bud ADC specific immunoassay (ADC IA), mouse anti-dexamethasone IgG1 (MEB113.53F3.104A)-Biotin (Merck) was coated on to MSD Streptavidin multi-array 96-well plate, and MEB113.53F3.104A-SULFO-TAG was used as the detection reagent.

\section{Anti-CD74-Phos-Bud interacting protein in C57BL/6 J mouse plasma}

Anti-CD74-Phos-Bud was immune-purified from spiked C57BL/6 J mouse plasma using NanoLink Streptavidin Magnetic beads (Solulink, San Diego, CA) immobilized with biotin-SP-conjugated AffiniPure $\mathrm{F}\left(\mathrm{ab} \mathrm{b}^{\prime}\right) 2$ fragment 
goat anti-human IgG $(\mathrm{H}+\mathrm{L})$ (Jackson ImmunoResearch) with $3 \mathrm{~h}$ incubation at $4{ }^{\circ} \mathrm{C}$. After capture, beads were separated from plasma using a magnetic rack and washed five times with $0.1 \%$ RapiGest (Waters) in TBS $1 \times$ solution. Samples were eluted with $30 \mu \mathrm{L}$ of $0.25 \%$ formic acid solution and neutralized by the addition of TRIS $\mathrm{HCl}(1 \mathrm{M})$. Samples were heated for $3 \mathrm{~min}$ at $80^{\circ}$ $\mathrm{C}$ for denaturation, reduced with DDT (final concentration of $5 \mathrm{mM}$ ) for $30 \mathrm{~min}$ at $60{ }^{\circ} \mathrm{C}$, and alkylated with iodoacetamide (final concentration of $15 \mathrm{mM}$ ) for $30 \mathrm{~min}$ at room temperature in dark. Digestion was performed by addition of $2.5 \mu \mathrm{g}$ of trypsin (Promega, Madison, WI) to each sample, and incubation for $4 \mathrm{~h}$ at $37^{\circ}$ C. Digestion was quenched by addition of $\mathrm{HCl}$ (final concentration of $200 \mathrm{mM}$ ) and samples were further incubated at $37{ }^{\circ} \mathrm{C}$ for $45 \mathrm{~min}$ for hydrolysis of remaining RapiGest. Samples were centrifuged at $14,000 \mathrm{rpm}$ for $10 \mathrm{~min}$ at $4{ }^{\circ} \mathrm{C}$, and $4 \mu \mathrm{L}$ of digests were injected in a LC-MS/MS system NanoAcquity (Waters)/ LTQ-Orbritrap XL (ThermoScientific) with a $60 \mathrm{~min}$ linear gradient from 5 to $56 \%$ Buffer B (Buffer A: 0.1\% formic acid aqueous solution; Buffer B: $0.1 \%$ formic acid in acetonitrile) at $0.4 \mu \mathrm{L} / \mathrm{min}$. Search was performed using the Proteome Discoverer Software (ThermoScientific).

\section{DyLight $^{\mathrm{TM}} 650$ labeling of antibodies}

DyLight $^{\text {tax }} 650$ labeling kits (ThermoScientific) were used to conjugate an N-hydroxysuccinimide ester fluorescence dye (excitation at $652 \mathrm{~nm}$ and emission at $672 \mathrm{~nm}$ ) to anti-CD74, anti-CD74-Phos-Bud, and isotype matched control antibody (mAb-C), Pep-ADC, and $\mathrm{mAb3}$, using the method described in previous publication from our group (Brunn et al., 2016).

In vitro stability assessment of DyLight 650 labeled antiCD74, anti-CD74-Phos-Bud, and isotype control antibody (mAb-C) by SEC-HPLC

For assessing stability in mouse plasma in vitro, DyLight 650 labeled anti-CD74, anti-CD74-Phos-Bud and isotype matched control antibody $(\mathrm{mAb}-\mathrm{C})$ were incubated at $37{ }^{\circ} \mathrm{C}$ in $\mathrm{C} 57 \mathrm{BL} / 6 \mathrm{~J}$ mouse plasma $(100 \mu \mathrm{L})$ at a final concentration of $80 \mu \mathrm{g} / \mathrm{mL}$, samples were taken out and snap frozen at designated time points, and stored at $80{ }^{\circ} \mathrm{C}$ until analysis. For SEC-HPLC analysis, $25 \mu \mathrm{L}$ of plasma samples from time points were applied onto a BioSep-SEC-S3000 column (Phenomenex, Torrance, CA) at $1 \mathrm{~mL} / \mathrm{min}$ elution rate with $\mathrm{PBS}$ as a mobile phase for $15 \mathrm{~min}$, and analyzed using an Agilent 1200 HPLC system (Agilent Technologies, Santa Clara, CA). The effluent was monitored continuously at $280 \mathrm{~nm}$ and by the net fluorescence intensity at an excitation wavelength of $646 \mathrm{~nm}$ and emission of $674 \mathrm{~nm}$, as described previously (Brunn et al., 2016).
Biodistribution of DyLight 650 labeled anti-CD74-PhosBud and unconjugated anti-CD74-011 mAb in mice Transgenic human CD74 mice (B6.Cg-Tg(CD74)AR194Ayr/j) and normal wild type C57BL/6 J female littermates (WT) ( $n=2 /$ group/time point) were given $5 \mathrm{mg} / \mathrm{kg} \mathrm{IV}$ bolus of DyLight 650 labeled-anti-CD74-Phos-Bud. A separate group of wild type littermates $(n=2 /$ time point) were administered with $5 \mathrm{mg} / \mathrm{kg}$ of DyLight 650 labeled-anti-CD74-011. Animals were euthanized with carbon dioxide followed by terminal cardiac puncture. Blood, plasma, and selected tissues were harvested to measure drug concentration. Whole blood samples were collected into K2-EDTA CapiJect microcollection tubes (Terumo Medical Corporation, Somerset, NJ) and placed on ice. For drug analysis in whole blood, samples were aliquoted into polypropylene vials (Corning Glassworks, Corning, NY) and stored at $-80{ }^{\circ} \mathrm{C}$. Plasma was separated from whole blood via centrifugation for $6 \mathrm{~min}$ at $6000 \times \mathrm{g}$ at $4{ }^{\circ} \mathrm{C}$, and stored at $-80{ }^{\circ} \mathrm{C}$. For tissue lysates, organ samples were collected and immediately placed into $2-\mathrm{ml}$ Precellys Lysing Tubes (Bertin Technologies, Rockville, $\mathrm{MD})$, weighed, and frozen by placing on dry ice. To prepare lysates, upon partial thawing, a 1:5 dilution of Dulbecco's PBS containing 1\% Triton X-100 (MP Biomedicals, Solon, $\mathrm{OH}$ ) and $1 \times$ Halt Protease Inhibitor single use cocktail (ThermoFisher Scientific) was added to the samples. Then, tissue slurries were prepared using a Precellys Evolution Homogenizer (Bertin Technologies). The slurry was centrifuged $\left(10,000 \times \mathrm{g}\right.$ at $4{ }^{\circ} \mathrm{C}$ for $\left.10 \mathrm{~min}\right)$ and the tissue lysate supernatants were collected and either processed immediately or stored at $-80{ }^{\circ} \mathrm{C}$ until analysis.

\section{Determination of DyLight 650 labeled -anti-CD74-Phos- Bud and anti-CD74-011 mAb concentration in tissue} samples by fluorescence emission-linked analysis (FELA) For assessment of tissue drug concentration, the collected blood, plasma, and tissue lysate samples or a set of corressponding blank tissue samples were diluted 1:10 (final dilution) with tissue lysis buffer $(1 \times$ DPBS with $1 \%$ Triton X-100). The diluted samples $(150 \mu \mathrm{L})$ were transferred to 96-well polystyrene plates with low fluorescence background for analysis in the Glomax Multi-Detection system microplate reader (Promega). The microplate reader was equipped with a fluorescence optical filter featuring excitation and emission wavelengths of $625 \mathrm{~nm}$ and 660 to $720 \mathrm{~nm}$, respectively.

For each DyLight 650 labeled antibody, fluorescence intensity calibration curves were established by serially diluting spiked blood and liver lysate. A linear correlation function was fitted to the data using best-fit parameters on Microsoft Excel. The resulting blood calibration curve equation was used to fit unknown blood and spleen lysate samples, and the liver calibration 
curve equation was used to fit unknown liver lysate samples. Concentrations of DyLight-650 labeled antibodies were calculated as microgram equivalents per gram of wet tissue or as microgram equivalents per $\mathrm{mL}$ of blood. Subsequently, tissues to blood ratios were calculated by dividing concentration in respective tissue by concentration in blood at the designated time point.

\section{Assessment of bioactive and total Pep-ADC in mice}

In order to measure the bioactivity of Pep-ADC in plasma (Bioassay), plasma samples from C57BL/6 J male mice with diet induced obesity (DIO) dosed with $10 \mathrm{mg} /$ kg IV bolus of Pep-ADC were incubated with GLP1R transfected Chinese hamster ovarian $(\mathrm{CHO})$ cells for $1 \mathrm{~h}$. The reactions were stopped by adding cell-lysis buffer from cAMP CISBIO kit (Cisbio, Bedford, MA). A calibration curve was established using different amount of Pep-ADC spiked into plasma to stimulate GLP1R-CHO cells and quantify cAMP release in a 96-well corning white plate using cAMP CISBIO kit. Bioactivity of Pep-ADC was back-calculated and reported as $\mu \mathrm{g} / \mathrm{mL}$.

To determine the total antibody level (Total mAb3 assay), MSD immunoassay was used. Plasma samples from Pep-ADC dosed animals were applied to Streptavidin Gold Multi-Array 96-well Plate (MSD) coated with mouse anti-Human IgG4-Biotin (SouthernBiotech) as a capture reagent, and SULFO-TAG-mouse anti-Human IgG (Southern Biotech) was used for detection.

\section{Pep-ADC intact mass analysis by AP-LC-MS}

Mouse study: C57BL/6 J male mice $(n=3)$ with diet induced obesity were dosed with $3 \mathrm{mg} / \mathrm{kg}$ IV bolus of Pep-ADC. Plasma samples collected at day 1, 3, 7, and 10 were processed for intact mass analysis.

Non-human primates study: Treatment naïve male rhesus monkeys $(\mathrm{n}=3)$ weighing $6-7.1 \mathrm{~kg}$ were fasted overnight and dosed with $3 \mathrm{mg} / \mathrm{kg}$ IV bolus of Pep-ADC. Plasma samples collected at 5 min, day 1 , day 3 , day 7 , day 10 , and day 14 were processed for intact mass analysis.

Pep-ADC was retrieved from plasma samples from both studies by affinity purification for LC-MS as follows. Nanolink Streptavidin Magnetic beads (Solulink) were preloaded with biotinylated polyclonal goat anti human IgG (SouthernBiotech). Preloaded magnetic beads $(20 \mu \mathrm{l})$ at $2.5 \mathrm{mg} / \mathrm{ml}$ in TBS pH 7.4, 0.02\% Rapigest SF Surfactant (Waters) was added to $30 \mu \mathrm{l}$ of K2-EDTA plasma sample. Captured Pep-ADC was eluted in $30 \mu \mathrm{l}$ of $0.25 \%$ formic acid (FA), reduced with $5 \mathrm{mM}$ TCEP for $30 \mathrm{~min}$ at $60{ }^{\circ} \mathrm{C}$, and $10 \mu \mathrm{l}$ was injected into Waters Acquity UPLC I class on line with Waters Synapt G2S QTOF mass-spectrometer. Reverse phase chromatography was used on the Poros R2/10 column
$(2.1 \times 30 \mathrm{~mm})$ (Applied Biosystems, Waltham, MA) with flow rate $0.1 \mathrm{ml} / \mathrm{min}, 7 \mathrm{~min}$ gradient $30 \%$ to $58 \% \mathrm{~B}, 65^{\circ}$ C. Buffer A was water, $0.1 \%$ FA, buffer B was $90 \%$ Acetonitrile, $0.1 \%$ FA. Mass Spectrometry conditions were: capillary voltage of $3.2 \mathrm{kV}$, cone voltage of $80 \mathrm{~V}$, desolvation temperature $450{ }^{\circ} \mathrm{C}$. Mass data was acquired in $\mathrm{m} / \mathrm{z}$ mass range of 500-4000. The mass spectrum was deconvoluted and integrated using MassLynx software (Waters).

\section{Pep-ADC quantitative mass spectrometry based assay (LC-MRM)}

$50 \mu \mathrm{L}$ of solulink magnetic beads were coated by rotation with $250 \mu \mathrm{L}$ of goat anti-human IgG (monkey absorbed)-Biotin (SouthernBiotech) for $30 \mathrm{~min}$ at room temperature. The beads were washed 3 times with TBS/ $0.02 \%$ RapiGest and resuspended in $50 \mu \mathrm{L}$ of TBS/0.02\% RapiGest. For affinity enrichment, $5 \mu \mathrm{L}$ of bead was incubated with $30 \mu \mathrm{L}$ of plasma and TBS/0.02\% RapiGest up to $50 \mu \mathrm{l}$ for $30 \mathrm{~min}$ on a rotator. The beads were washed 3 times with TBS/0.02\% RapiGest and once with TBS ( $\mathrm{pH} 7.4$ ), eluted with $30 \mu \mathrm{L}$ of $0.1 \%$ formic acid, and neutralized with $2.5 \mu \mathrm{L}$ of $1 \mathrm{M}$ ammonium bicarbonate.

$50 \mathrm{mM}$ TCEP was added for reduction and the mixture incubated for $30 \mathrm{~min}$ at $60{ }^{\circ} \mathrm{C}$. Digestion was done with $0.25 \mu \mathrm{g}$ of trypsin for $5 \mathrm{~h}$ at $37{ }^{\circ} \mathrm{C} .1 \mathrm{pmol}$ of labeled peptides spanning residue 1 to 12 (representing intact molecule) and residue 24 to 30 (representing M1) was added as internal standard. $5 \mu \mathrm{L}$ was injected into an Acquity TSQ Vantage for multiple reactions monitoring of R1-R12 and R24-30 peptides.

\section{Biodisposition of Pep-ADC in mice}

Normal C57BL/6 J mice ( $n=2 /$ group/time point) were administered a single $3 \mathrm{mg} / \mathrm{kg}$ IV dose of either DyLight 650 labeled Pep-ADC or unconjugated mAb3. Plasma and tissue samples were collected at $1 \mathrm{~h}$, day $1,2,3,5,7$, 9 , and day 14 post dose.

To generate plasma concentration vs time profiles, DyLight 650 labeled drug concentration in plasma was determined by FELA as described previously for anti-CD74 studies.

To determine in vivo stability of DyLight 650 labeled Pep-ADC and unconjugated mAb3 by SEC-HPLC, undiluted plasma samples collected at $1 \mathrm{~h}$, day 2, 5, 9 and day 14 from each group were applied onto a BioSep-SEC-S3000 column (Phenomenex) at $1 \mathrm{~mL} / \mathrm{min}$ elution rate with PBS as a mobile phase for $15 \mathrm{~min}$, and analyzed using an Agilent 1200 HPLC system (Agilent Technologies). The effluent was monitored continuously at $280 \mathrm{~nm}$ and by the net fluorescence intensity at an excitation wavelength of $646 \mathrm{~nm}$ and emission of $674 \mathrm{~nm}$, as described previously (Brunn et al., 2016). 
To determine cellular disposition of the labeled antibodies, $1 \mathrm{~h}$ and day 1 post dose pancreas sections cut from formalin fixed paraffin embedded (FFPE) tissue blocks were deparaffinized and rehydrated with serial passage through changes of xylene and graded ethanols for DyLight 650 immunohistochemistry (IHC). All slides were subjected to heat induced epitope retrieval in TRS solution ( $\mathrm{pH}$ 6.1) (Dako, Carpineteria, CA). Endogenous peroxidase in tissues was blocked by incubation of slides in $3 \%$ hydrogen peroxide solution prior to incubation with primary antibody, FITC-conjugated anti-DyLight 650 clone 12A3 (Merck) for $60 \mathrm{~min}$. Antigen-antibody binding was visualized via application of rabbit anti-FITC antibody (Invitrogen, Carlsbad, CA) then Envision Rabbit HRP (Dako) and application of 3, 3' diaminobenzidine (DAB) chromogen (Dako). Stained slides were counterstained with hematoxylin and coverslipped for review.

\section{Pharmacokinetics}

All pharmacokinetic parameters were estimated or calculated by non-compartmental analysis (NCA) using Phoenix $^{\oplus}$ WinNonlin $^{\oplus}$ software (Certara, Princeton, NJ). Model 201 (IV input bolus) was used for the NCA.

\section{Results}

\section{Case-study 1: Anti-inflammatory steroid-ADCs}

Systemic anti-inflammatory drugs are often used in the treatment of chronic conditions such as inflammatory bowel disease (Baumgart and Sandborn, 2007) and asthma (Lipworth, 1999). As a class, steroids are largely not cell or tissue specific and their systemic use is dose-limited due to harmful side effects (Brunton, 2011). Developing a targeted delivery of the most potent immune system repressors through an antibody-drug conjugate could provide a more effective dose and dosing rational for enhanced efficacy without triggering nonspecific detrimental side effects (Kern et al., 2016a).

Through site specific conjugation in the $\mathrm{CH} 1$ domain (Axup et al., 2012), we coupled potent anti-inflammatory molecules, dexamethasone and budesonide, to different monoclonal antibodies aimed at surface receptors broadly expressed on immune cells involved in inflammation. In this modality, the ADC should remain intact in the systemic circulation, bind to its intended target on the surface of immune cells followed by target-mediated internalization and drug release in the lysosomal compartment. The active drug is then released to engage glucocorticoid receptors inside the cell. In addition to their affinity and specificity, it is expected that these antibody conjugates should retain ideal pharmacokinetic properties mainly affected by target-mediated clearance and display a pattern of organ disposition similar to normal endogenous IgGs.
Anti-CD25 mAb conjugated to dexamethasone with cathepsin or phosphate linker: Importance of linker stability

A monoclonal antibody against CD25 or Interleukin - 2 receptor alpha chain (IL-2R $\alpha$ ), expressed in a subset of immune cells (Triplett et al., 2012), was coupled to dexamethasone (Dex) using either a novel proprietary phosphate based linker (anti-CD25-Phos-Dex) (Kern et al., 2016a) or a cathepsin based linker (anti-CD25-Cat-Dex) (Kern et al., 2016b). In order to fully characterize the ADC stability in mouse plasma, several assays were developed. Initially these included: A total antibody immunoassay measuring anti-CD25 antibody still capable of binding the target regardless of presence or absence of payload (target-capture and anti-Fc detection); A conjugate specific ADC immunoassay (target capture and anti-Dex detection); And a LC-MS assay to measure free Dex.

Mouse neat plasma spiked with anti-CD25-Phos-Dex was incubated over the course of 18 days at $37{ }^{\circ} \mathrm{C}$. The total antibody and ADC specific immunoassays showed a constant concentration across all time points (Fig. 2a). Likewise, the LC-MS assay for free Dex showed no appearance of unconjugated payload at any time-point consistent with the intactness of this construct in plasma.

In contrast, the same ADC but with the cathepsin linker (anti-CD25-Cat-Dex conjugate) showed a very different stability-time profile. Total antibody levels were unchanged and no free Dex was detected (Fig. 2b). However, the ADC proved to be highly unstable as illustrated by a dramatic decrease in concentration over time measured by the ADC-specific immunoassay (Fig. 2b). To investigate the unexpected lack of stability of anti-CD25-Cat-Dex in plasma, we developed a method based on affinity purification followed by intact mass measurement by LC-MS (AP-LC-MS). Anti-CD25-Cat-Dex spiked in plasma was retrieved using antigen-bound beads and its mass was measured on a Q-TOF mass spectrometer Synapt G2S. The analysis was consistent with a clipping site in the linker moiety at a $\mathrm{C}-\mathrm{O}$ bond, between the linker and the drug moieties, which was not the part of the predicted cathepsin cleavage site (Fig. 2c). Linker cleavage at this novel site explains the decrease in intact $\mathrm{ADC}$ in the immunoassay and the absence of free drug by LC-MS as the drug remains attached to a part of the broken linker. The same clipping was also observed when anti-CD25-Cat-Dex was incubated in phosphate buffered saline (PBS). Regardless of other approaches, the implementation of an AP-LC-MS intact mass method should become an essential tool to monitor the integrity of the ADCs.

Contrary to the cathepsin sensitive linker ADC (anti-CD25-Cat-Dex) instability, the AP-LC-MS intact mass analysis of anti-CD25-Phos-Dex showed no evidence of drug release or linker instability resulting in a constant drug to antibody ratio with molecular weights 
A

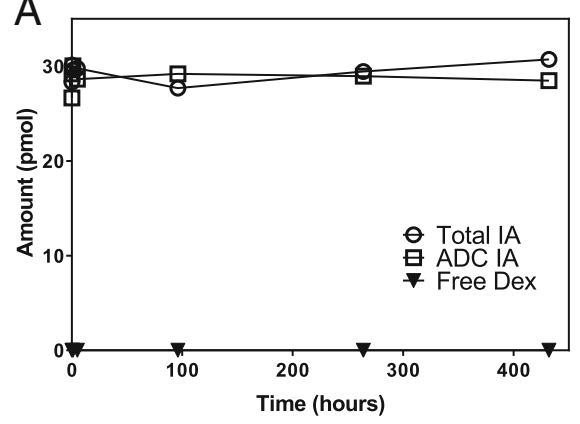

B

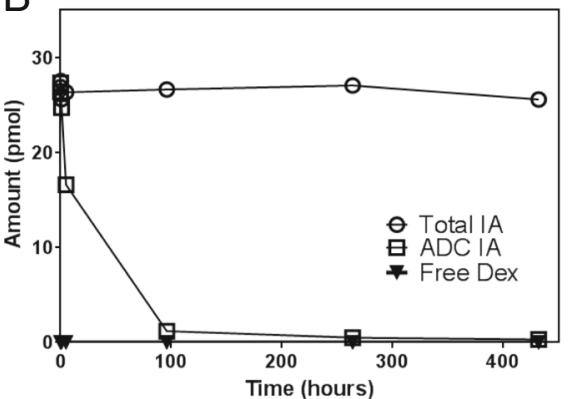

C

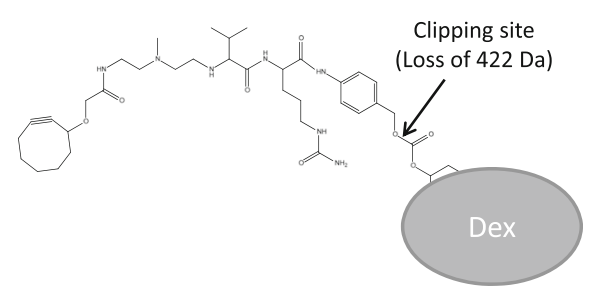

Fig. 2 In vitro stability of anti-CD25-Phos-Dex and anti-CD25-Cat-Dex in mouse plasma. To assess the trend in stability of these antibodies, AntiCD25-Phos-Dex (a) or anti-CD25-Cat-Dex (b) was spiked in normal male DBA 1 mouse plasma for up to 18 days at $37{ }^{\circ} \mathrm{C}$. After incubation, the levels of antibody was determined by total antibody immunoassay (Total IA) and the levels of intact ADC was determined by ADC specific immunoassay (ADC IA) on plasma samples using Mesoscale Discovery (MSD) sandwich immunoassay, and free dexamethasone was determined by LC-MS (Free Dex). Amounts in picomole (pmol) versus time are plotted to compare across different methods of analysis. Values represent the results of a single incubation at each time point. Panel c shows the unexpected site of cleavage in the cathepsin linker of anti-CD25-Cat-Dex

comparable to the stock solution at all-time points (unpublished observations). This result was consistent with ADC-specific immunoassay results (Fig. 2a).

The potential relevance of in vitro ADC analysis depends largely on their translatability to appropriate preclinical models for safety and efficacy. These in turn should be selected based on their relevance to the human physiology and expected mechanism of action (MoA) of the ADC and free drug. Therefore, the stability of anti-CD25-Phos-Dex was further tested in a preclinical PK study. Mice were administered a single intravenous injection of $4 \mathrm{mg} / \mathrm{kg}$ of anti-CD25-Phos-Dex. Both immunoassays (total and ADC) showed overlapping concentrations with a typical IgG PK profile (unpublished observations). Likewise, the total mass spectrum for the ADC showed an identical profile to the stock solution and unchanged drug to antibody ratio of 2 at all time points. These results are consistent with the overall good stability of the anti-CD25-Phos-Dex including the drug, linker, and antibody components both in vitro and in vivo.

\section{Anti-CD74 mAb conjugated to budesonide with phosphate linker: Importance of the targeting antibody properties}

In a different ADC construct with a monoclonal antibody targeting CD74, a cell surface receptor which is known to associate with MHC class II molecule (Borghese and Clanchy, 2011), a more potent anti-inflammatory steroid, budesonide (Bud), was conjugated using an identical phosphate linker at the same amino acid residue position in the $\mathrm{CH} 1$ domain. The systemic stability of the resulting ADC (anti-CD74-Phos-Bud) was characterized following IV dosing in mice at 3,10 , and $30 \mathrm{mg} / \mathrm{kg}$. The plasma levels of total $\mathrm{mAb}$ versus conjugate-specific immunoassay results showed an apparent linker and/or payload instability (Fig. 3), contrary to the first example of anti-CD25-Phos-Dex. However, the AP-LC-MS analysis indicated a constant peak, identical to the original dosing material demonstrating the intactness of the ADC construct up to $6 \mathrm{~h}$, after which strong peak broadening was observed and the total ion chromatograms could not be deconvoluted, suggesting heterogeneity. This could be due to severe conjugate modifications, aggregation, or protein interactions. In addition, no free Bud could be detected by LC-MS at any time point. Therefore, additional studies were implemented to better understand these discrepancies. Anti-CD74-Phos-Bud was incubated in mouse plasma for 14 days at $37^{\circ} \mathrm{C}$ and retrieved by pull-down for tryptic digestion and analysis by LC-MS for identification of ADC associated plasma proteins. Analysis of these samples and a control sample 

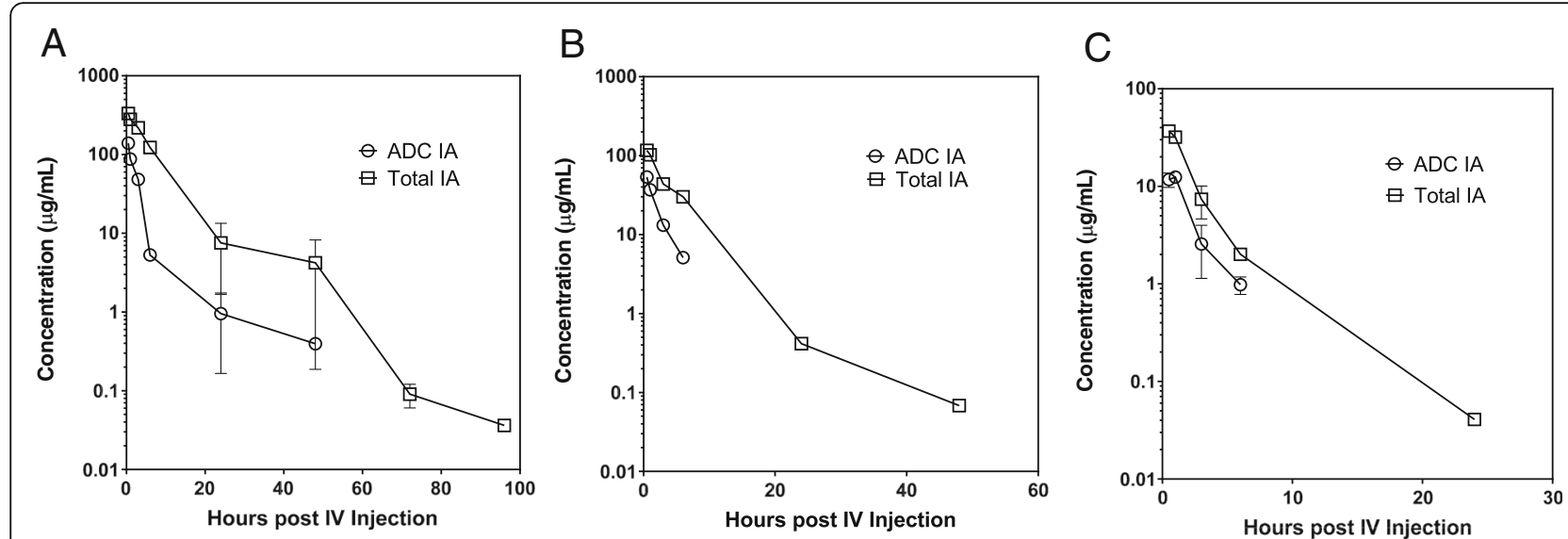

Fig. 3 In vivo stability of anti-CD74-Phos-Bud. To assess the stability of anti-CD74-Phos Bud in mice, the levels of antibody was determined by total antibody immunoassay (Total IA) and levels of intact ADC was determined by ADC specific immunoassay (ADC IA) on plasma samples from human CD74+ transgenic (Tg) mice IV dosed with $30 \mathrm{mg} / \mathrm{kg}(\mathbf{a}), 10 \mathrm{mg} / \mathrm{kg}$ (b) and $3 \mathrm{mg} / \mathrm{kg}$ (c). Data plotted are mean from two mice per time point. Error bars correspond to the range. Error bars smaller than the symbol are not visible

with no ADC spiked in the original mouse plasma revealed the presence of several unexpected, off-target ADC-associated proteins (Fig. 4). These included: alpha-2 macroglobulin, ceruloplasmin, complement C3, albumin, fibrinogen beta, and murinoglobulin 1. Using a different approach, anti-CD74-Phos-Bud and unconjugated (naked) anti-CD74 were labeled using a DyLight-650 fluorescent dye to follow their size exclusion chromatography (SEC) profile over time upon incubation in mouse plasma at $37^{\circ} \mathrm{C}$. Samples were analyzed on an Agilent 1100 high pressure liquid chromatography

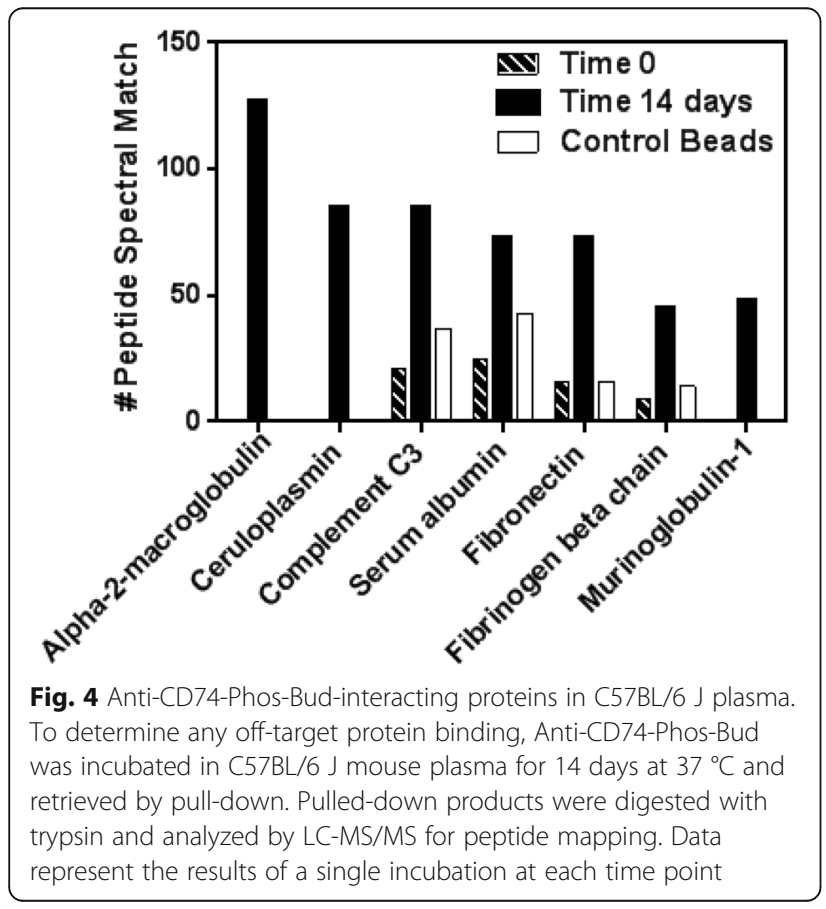

(HPLC) system equipped with an in-line fluorescent detector. The resulting chromatographic profiles (Fig. 5a and b) indicated antibody instability as shown by the formation of high molecular weight (HMW) complexes for both constructs. By day 14 of incubation, only $53 \%$ of anti-CD74-Phos-Bud and 60\% of drug unconjugated anti-CD74 antibody remained as a single intact monomeric IgG peak. A control antibody (Fig. 5c) remained at 96\% in the same conditions. The immunoassay discrepancies between total anti-CD74 versus intact ADC values may be attributed to assay interferences due to antibody aggregation or off-target association with plasma proteins preventing payload detection. The identification of anti-CD74-Phos-Bud HMW complex formation in plasma was consistent with the off-target interactions identified by LC-MS, and pointed to a potential flaw in the properties of the anti-CD74 mAb moiety but not in the linker or the payload or the conjugation process.

\section{Unconjugated anti-CD74 mAb shows off-target clearance mechanism in mice without CD74 target}

Clearance of free IgGs and small, non-precipitating IgG complexes happen primarily by interactions with Fc receptors ( $F c R s)$ and non-specific protein clearance via fluid-phase endocytosis (Nash et al., 2001; Rojas et al., 2005; Takai, 2002). These pathways are expected to drive the elimination of anti-CD74 in species without the target expression or binding. To determine the PK properties of this anti-CD74 antibody, wild C57BL/6 J mice were administered a single intravenous dose of unconjugated anti-CD74. As show in Table 1, non-linear PK properties were observed for this antibody (Table 1). 


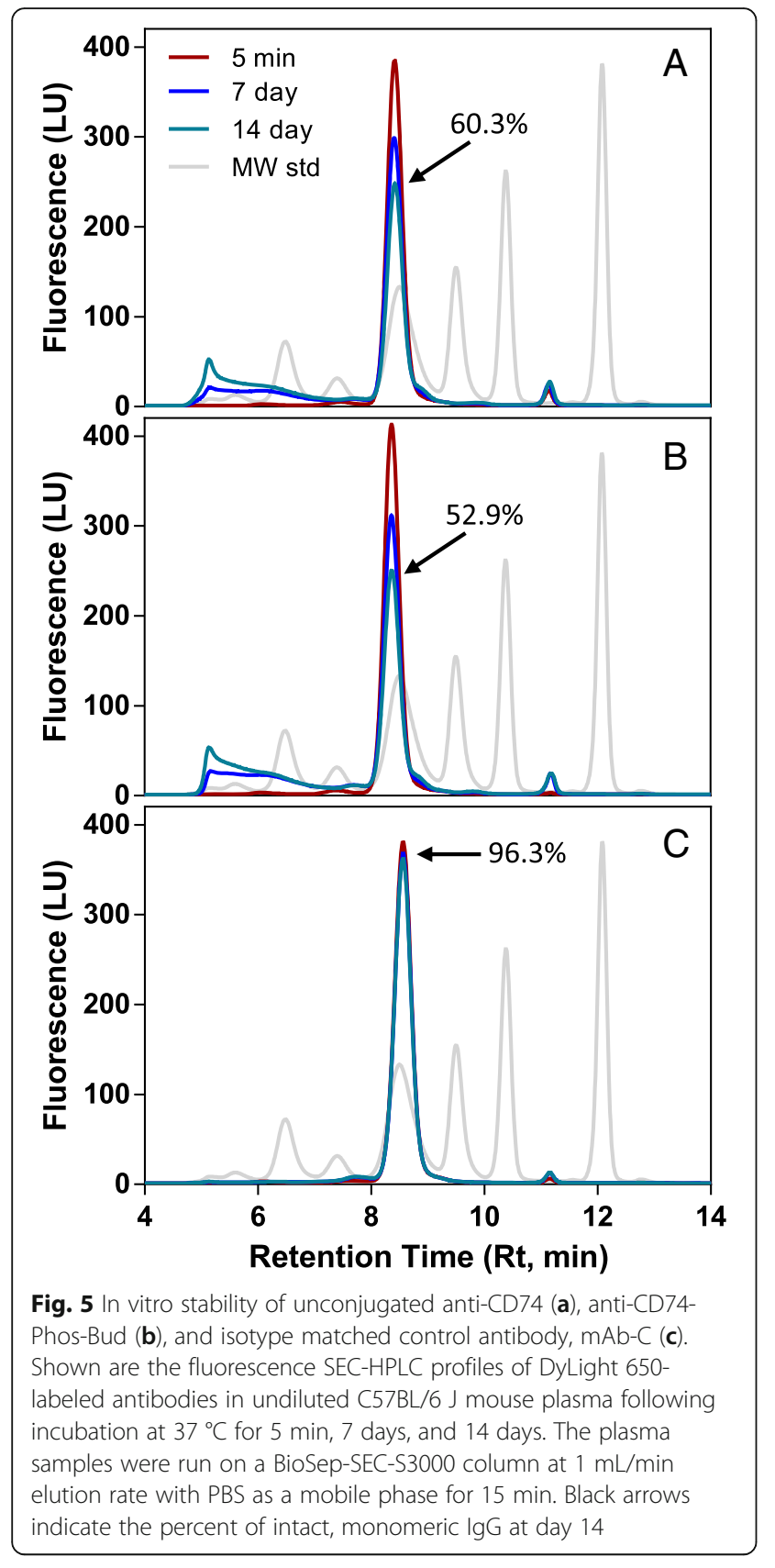

$A C_{0-I N F}:$ Area under the curve from zero to infinity; $C L$ : Clearance; $C_{\text {max }}$ : Observed maximum concentration; $\mathrm{t1}_{1 / 2}$ : Terminal half-life; $V_{s s}$ : Volume of distribution at steady state

Frequently, non-linear PK of mAbs may be explained by target mediated disposition (TMD). TMD is a saturable process and it is characterized by decreasing clearance with increasing doses. On the contrary, clearance of unconjugated anti-CD74 appeared to be higher when higher doses were administered. In addition, since this anti-CD74 antibody does not recognize the murine target receptor, its PK was not expected to reflect TMD.
Table 1 PK parameters following IV administration of anti-CD74 to C57BL/6 J mice

\begin{tabular}{llllll}
\hline $\begin{array}{l}\text { Dose } \\
(\mathrm{mg} / \mathrm{kg})\end{array}$ & $\begin{array}{l}\mathrm{t}_{1 / 2} \\
(\text { day })\end{array}$ & $\begin{array}{l}\mathrm{C}_{\max } \\
(\mu \mathrm{g} / \mathrm{mL})\end{array}$ & $\begin{array}{l}\mathrm{CL} \\
(\mathrm{mL} / \text { day } / \mathrm{kg})\end{array}$ & $\begin{array}{l}\mathrm{V}_{\mathrm{ss}} \\
(\mathrm{mL} / \mathrm{kg})\end{array}$ & $\begin{array}{l}\mathrm{AUC}_{0-\mathrm{INF}} \\
\left(\text { day }^{*} \mu \mathrm{g} / \mathrm{mL}\right)\end{array}$ \\
\hline 10 & 3.75 & 90.0 & 195 & 589 & 51.4 \\
3 & 3.42 & 27.8 & 70.3 & 295 & 42.7 \\
1 & 3.90 & 12.0 & 39.8 & 197 & 25.2 \\
0.3 & 3.97 & 2.72 & 31.5 & 170 & 9.52 \\
\hline
\end{tabular}

Here, observed increases in clearance at higher doses are consistent with the presence of a low affinity, high capacity off-target antibody sink (i.e., a non-specific clearance mechanism). This is, in general, an undesirable property for a targeting antibody that is characterized for its specificity and extended systemic half-life.

\section{Anti-CD74-Phos-Bud tissue disposition pattern in mice} with and without human CD74 target confirms off target effect with anti-CD74 $\mathrm{mAb}$

To gain a better understanding of the DMPK properties of Anti-CD74-Phos-Bud, and the relevance of target versus off-target interactions in the fate of anti-CD74-Phos-Bud in vivo, we utilized a transgenic (Tg) mouse strain that expresses the human CD74 receptor (Honey et al., 2004). The expression of this human receptor is driven by the endogenous analog murine promoter; therefore, these transgenic mice display abundant receptor expression in spleen and to a lesser degree in hepatic tissues. Since anti-CD74-Phos-Bud does not recognize murine CD74, wild type (WT) littermates were used to evaluate the effect of target versus off-target interactions in the distribution and elimination of this antibody-drug-conjugate. In addition, a different, unconjugated anti-CD74 monoclonal antibody (referred to as anti-CD74-011 mAb hereafter) was used as a control for background tissue uptake characteristic of a non-specific IgG clearance mechanism, with known negative organ accumulation and tissue to blood ratios below 1 . Mice were given an IV dose of $5 \mathrm{mg} / \mathrm{kg}$ of DyLight-650-labeled anti-CD74-Phos-Bud and anti-CD74-011 mAb. Figure 6 shows the $\mu \mathrm{g}$-equivalents/gram $(\mu \mathrm{g} / \mathrm{g})$ of wet tissue or $\mu \mathrm{g} / \mathrm{ml}$ of blood in $\mathrm{Tg}$ and WT mice. In concordance with the organ receptor expression levels, anti-CD74-Phos-Bud distributed extensively to the spleen and liver in the Tg mice with peak concentrations of $87 \mu \mathrm{g} / \mathrm{g}$ at $2 \mathrm{~h}$ in spleen and $43.5 \mu \mathrm{g} / \mathrm{g}$ at $6 \mathrm{~h}$ in liver. However, disposition to spleen and liver in the wild type littermates was also unusually high (34.1 and $33.7 \mu \mathrm{g} / \mathrm{g}$ ) six hours post IV dosing. In contrast, the spleen and liver drug levels in the anti-CD74-011 mAb clone group using wild type littermates were below $11 \mu \mathrm{g} / \mathrm{g}$ at all time points in both organs. Accordingly, anti-CD74-Phos-Bud tissue 

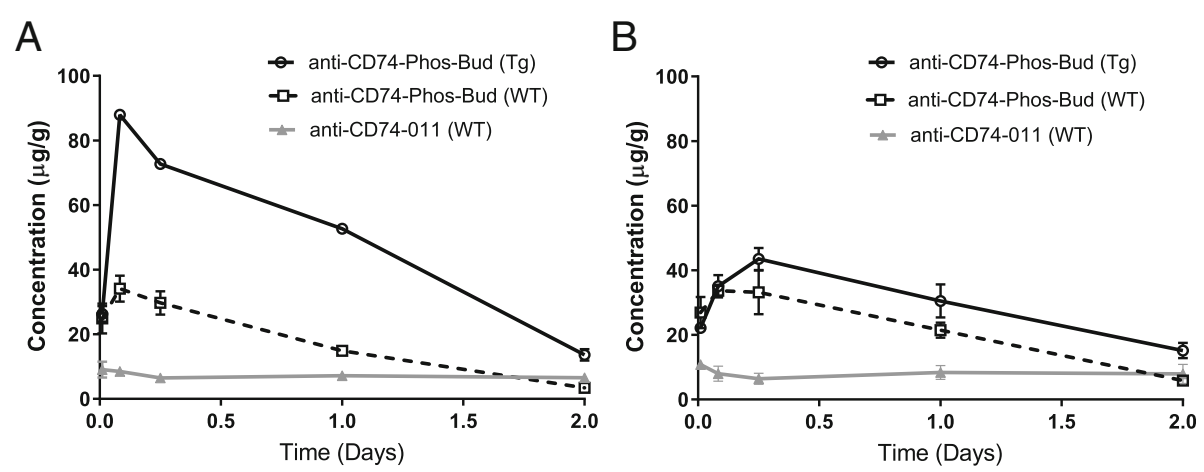

Fig. 6 Tissue distribution of anti-CD74-011 and anti-CD74-Phos-Bud. Microgram equivalent per gram concentration of antibodies in spleen (a) and liver (b) of WT or human $\mathrm{CD}_{4}{ }^{+}$transgenic $(\mathrm{Tg}$ ) mice were determined by fluorescence emission-linked assay at multiple time points over 2 days after $5 \mathrm{mg} / \mathrm{kg}$ IV dosing. An additional 15 min time-point was collected for anti-CD74-Phos-Bud in Tg mice. Data plotted are mean from two mice per time point. Error bars correspond to the range. Error bars smaller than the symbol are not plotted
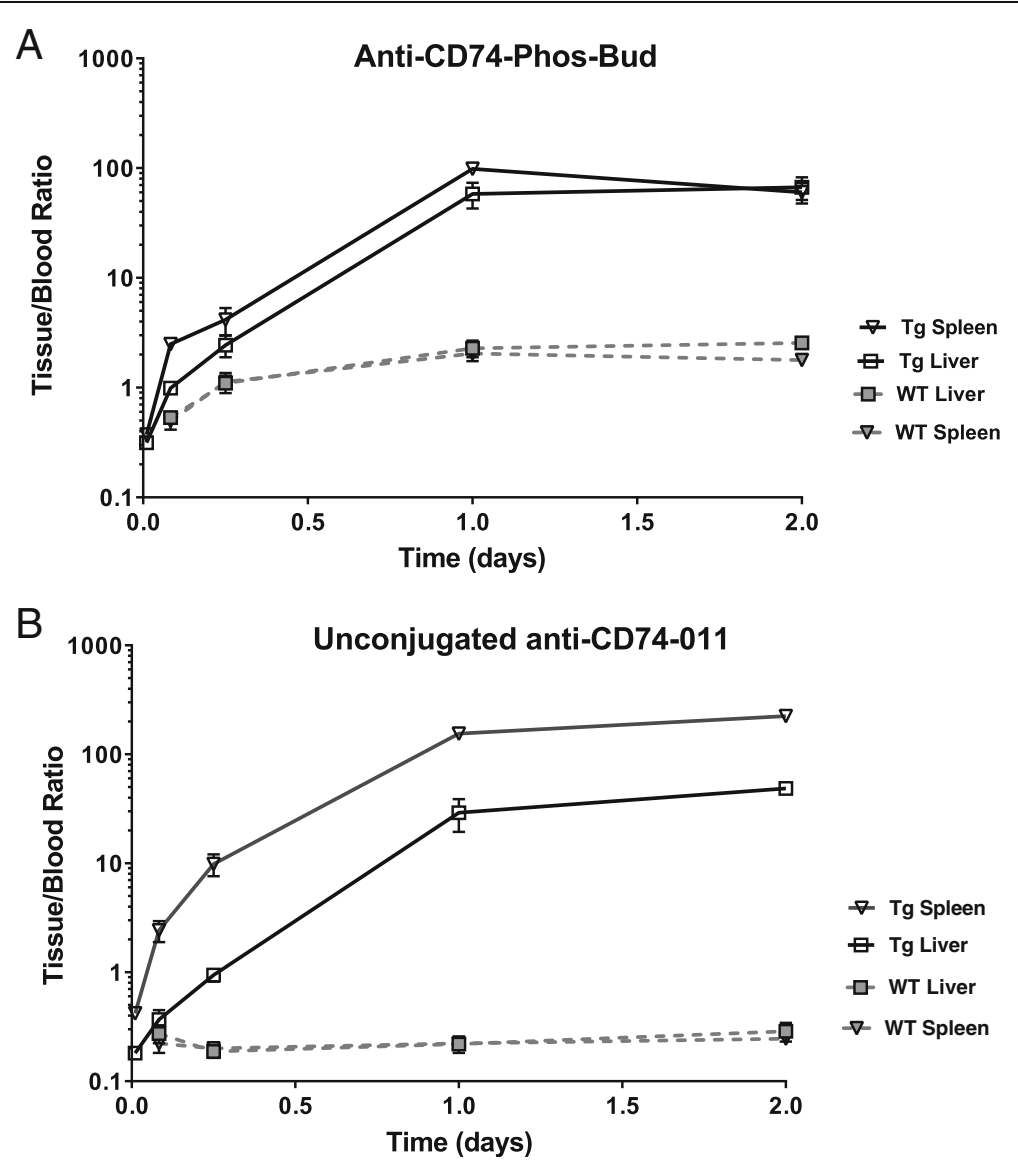

Fig. 7 Spleen and liver tissue to blood ratios of anti-CD74-Phos-Bud (a) and an unconjugated anti-CD74-011 (b) in wild type (WT) and human $\mathrm{CD}_{4}{ }^{+}$transgenic $(\mathrm{Tg})$ mice. Tissue/blood ratios were calculated from drug concentration measured by fluorescence emission-linked assay in blood and the tissues at 2 h, 6 h, 1 and 2 days after 5 mg/kg IV dosing. An additional 15 min time-point was collected for anti-CD74-Phos-Bud in Tg mice. Tissue/blood ratios greater than 1 are indicative of tissue uptake. Data plotted are mean from two mice per time point. Error bars correspond to the range. Error bars smaller than the symbol are not plotted 
to blood ratios were as high as 99 for the spleen at day 1 and 66.9 for liver at day 2 in Tg mice (Fig. 7a). However, tissue to blood ratios higher than 1 were also found in spleen and liver from wild type littermates consistent with off-target interactions. Overall these results demonstrated the presence of an antibody driven, off-target mechanism of tissue uptake and disposition, and were consistent with the identification of non-specific protein interactions in the circulation and undesirable PK for this construct. Based on these results, this anti-CD74 mAb was therefore not further considered as a lead therapeutic candidate. In this case, the intrinsic unfavorable properties of the antibody alone determined the overall poor fate of this ADC in vivo. This conclusion was further supported by observations with the anti-CD74-011 mAb, which demonstrated excellent stability in biomatrices. In a follow up disposition study, anti-CD74-011 mAb exhibited higher tissue to blood ratios in spleen compared to liver in human CD74 expressing transgenic mice at any evaluated time points, with ratio in spleen reaching as high as 224 at day 2 compared to 48.7 in liver (Fig. $7 \mathrm{~b}$ ). Furthermore, tissue-to-blood ratios in wild type mice for both tissues were lower than 0.5 at any evaluated time point (Fig. 7b). These observations were consistent with anti-CD74-011 $\mathrm{mAb}$ target-mediated uptake following administration to the transgenic mouse strain that expresses the human form of CD74 (Fig. 7b).

\section{Case-study 2: GLP1R/GCGR peptide-ADC (Pep-ADC): Importance of payload stability}

Due to their precise specificity, peptide drugs are gaining importance as therapeutic agents. However, their small size, rapid clearance rates, and systemic catabolism have limited their clinical potential and applications (McGregor, 2008; Sato et al., 2006). The use of balanced Glucagon -like peptide 1 receptor/Glucagon receptor (GLP1R/ GCGR) co-agonist has shown enhanced efficacy and safety relative to pure GLP1R agonists in the treatment of rodent obesity, with simultaneous improvement in glycemic control (Day et al., 2012; Day et al., 2009; Pocai et al., 2009).

Using site specific conjugation, we coupled a modified-for-stability GLP1R/GCGR co-agonist peptide (payload) to a residue in the CDR H1 of a non-targeting human $\mathrm{mAb}(\mathrm{mAb} 3)$ via a non-cleavable linker. The linked peptide-mAb3 immunoconjugate is referred to as Pep-ADC hereafter. In this modality, it is expected that the antibody moiety will provide a stable carrier for prolonged exposure in the circulation of the linked peptide due to reduced renal clearance and engagement of the FcRn recycle mechanism. In turn, this should result in a substantial improvement in the biological outcome compared to the co-agonist peptide dosed alone (Kompella and Lee, 1991). In order for this to occur, it is essential that both the linker and the bioactive peptide are designed with the required stability to match the enhanced pharmacokinetic properties conferred by the antibody conjugation. For measurements of total versus intact $\mathrm{ADC}$ concentrations, an immunoassay (Fc capture and Fc detection) and a cell based bioactivity (peptide-induced receptor activation) procedures were implemented.

\section{Immunoassay, cell based bioactivity, and mass spectrometric characterization helped to determine the pep-ADC stability issue in mice}

To characterize the metabolic fate of Pep-ADC in vivo, Pep-ADC was administered to mice at 1 and $10 \mathrm{mg} / \mathrm{kg}$ as a single intravenous injection. Plasma was collected over time and analyzed for both total ADC (mAb3 levels) and cell-based bioactivity (assessment of free and/ or conjugated active peptide). Previous in vitro work with the free peptide (Pep) had demonstrated that only the intact moiety retained receptor binding and signaling in this cell-based assay. Pharmacokinetic results (Table 2 and Fig. 8) demonstrated more than 2-fold differences in exposure and clearance between total $\mathrm{mAb} 3$ and bioactive measurements in a cell based assay. Therefore, the smaller exposure and increased clearance for the bioactive ADC compared to the total ADC -suggested a potential linker instability and/or peptide catabolism.

To further understand the molecular nature of Pep-ADC potency loss, we conducted an AP-LC-MS analysis. In agreement with the bioactivity assay data, the results showed that while the intact conjugated Pep-ADC decreased with time and eventually became undetectable by day 5 , several clipped variants (M1, M2, M3 and M4) representing degradation of the conjugated peptide at various positions became the predominant ADC species (Fig. 9a and b). A control group of mice dosed with the mAb3 only, without the conjugated linker-peptide, showed a constant peak (intact $\mathrm{mAb}$ ) at the same molecular weight at all tested time points (unpublished observations) indicating no catabolism of the antibody moiety itself. Mass difference calculations identified that the conjugated peptide clipping between residues 2/3 (M4), 25/26 (M1), 27/28 (M2) and 30/31 (M3) of the peptide sequence (Fig. 9c). All clipped M-variants are inactive in bioassay, as it is known that the removal

Table 2 Pharmacokinetic parameters following IV administration of Pep-ADC to C57BL/6 J mice

\begin{tabular}{llllll}
\hline Assay & $\begin{array}{l}\text { Dose } \\
(\mathrm{mg} / \mathrm{kg})\end{array}$ & $\begin{array}{l}\mathrm{t}_{1 / 2} \\
(\text { day })\end{array}$ & $\begin{array}{l}\mathrm{AUC}_{0-14} \\
(\text { day* } \mu \mathrm{m} / \mathrm{mL})\end{array}$ & $\begin{array}{l}\mathrm{CL} \\
(\mathrm{mL} / \text { day } / \mathrm{kg})\end{array}$ & $\begin{array}{l}\mathrm{V}_{\mathrm{ss}} \\
(\mathrm{mL} / \mathrm{kg})\end{array}$ \\
\hline Total mAb3 & 1 & 5.12 & 56.9 & 15.5 & 89.1 \\
& 10 & 4.76 & 657 & 13.9 & 69.0 \\
Bioassay & 1 & 2.55 & 28.5 & 34.9 & 49.3 \\
& 10 & 2.78 & 264 & 37.5 & 64.7 \\
\hline
\end{tabular}

$\mathrm{AUC}_{0-14}$ : Area under the curve from zero to 14 days; $\mathrm{CL}$ : Clearance; $\mathrm{t}_{1 / 2}$ : Terminal half-life; $\mathrm{V}_{\mathrm{ss}}$ : Volume of distribution at steady state 


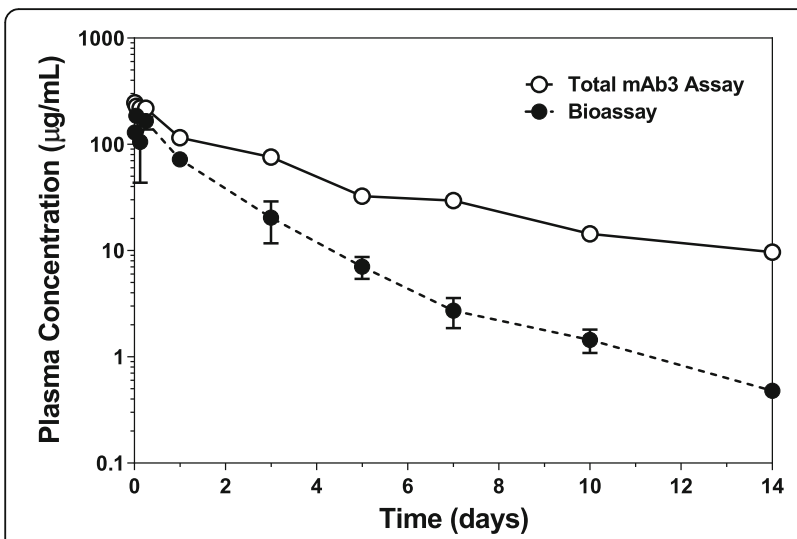

Fig. 8 The concentration time profile of Pep-ADC measured by two different assays. Plasma samples were collected at multiple time points over 14 days from mice IV dosed with $10 \mathrm{mg} / \mathrm{kg}$ of Pep-ADC, and measured for intact antibody concentrations by MSD assay (Total mAb3 assay) as well as bioactive ADC using a cell-based assay (Bioassay). Data plotted are mean from 3 mice. Error bars correspond to the S.D. calculated using GraphPad Prism 7. Error bars shorter than the symbols are not plotted

of the first two amino acids of Glucagon-like peptide-1 (GLP-1) by dipeptidyl peptidase 4 (DPP4) kills the activity of GLP-1 through GLP-1 receptor (GLP1R) (Knudsen and Pridal, 1996). This is also true for Pep-ADC, which is a modified Glucagon-like Peptide 1 receptor/Glucagon receptor (GLP1R/GCGR) co-agonist-bearing ADC. Finally, a mass spec-based quantitative assay was developed to measure the disappearance of the intact form and appearance of the main peptide catabolite (Fig. 10a). It confirmed that intact Pep-ADC disappeared fast and by day 2, only about $10 \%$ of intact Pep-ADC remained (Fig. 10b). Conversely, M1 increased for the first two days and then declined over the remaining 5 days as it was cleared and/ or transformed into M2 and M3 (Fig. 10b). Overall, these data were consistent with the bioactivity assay and intact $\mathrm{mAb}$ measurements, and confirmed M1 as one of the most abundant metabolites in the circulation. These results indicated a path forward in the rational design of improved ADC versions focused on strengthening the stability of the peptide moiety. It is important to note that although bioactive drug exposure can be further increased with potentially more stable peptide properties in the circulation, the current exposure to active drug in this ADC was considerably better than those of similar peptides when dosed alone with half-lives ranging in the order of minutes and elimination rates closer to glomerular filtration rates (Galaske et al., 1979). For free peptides in the circulation at pharmacological doses, two powerful mechanisms drive the fast elimination of these molecules mainly by renal clearance followed by systemic enzymatic degradation (Rabkin and Dahl, 1993). Peptide clearance by

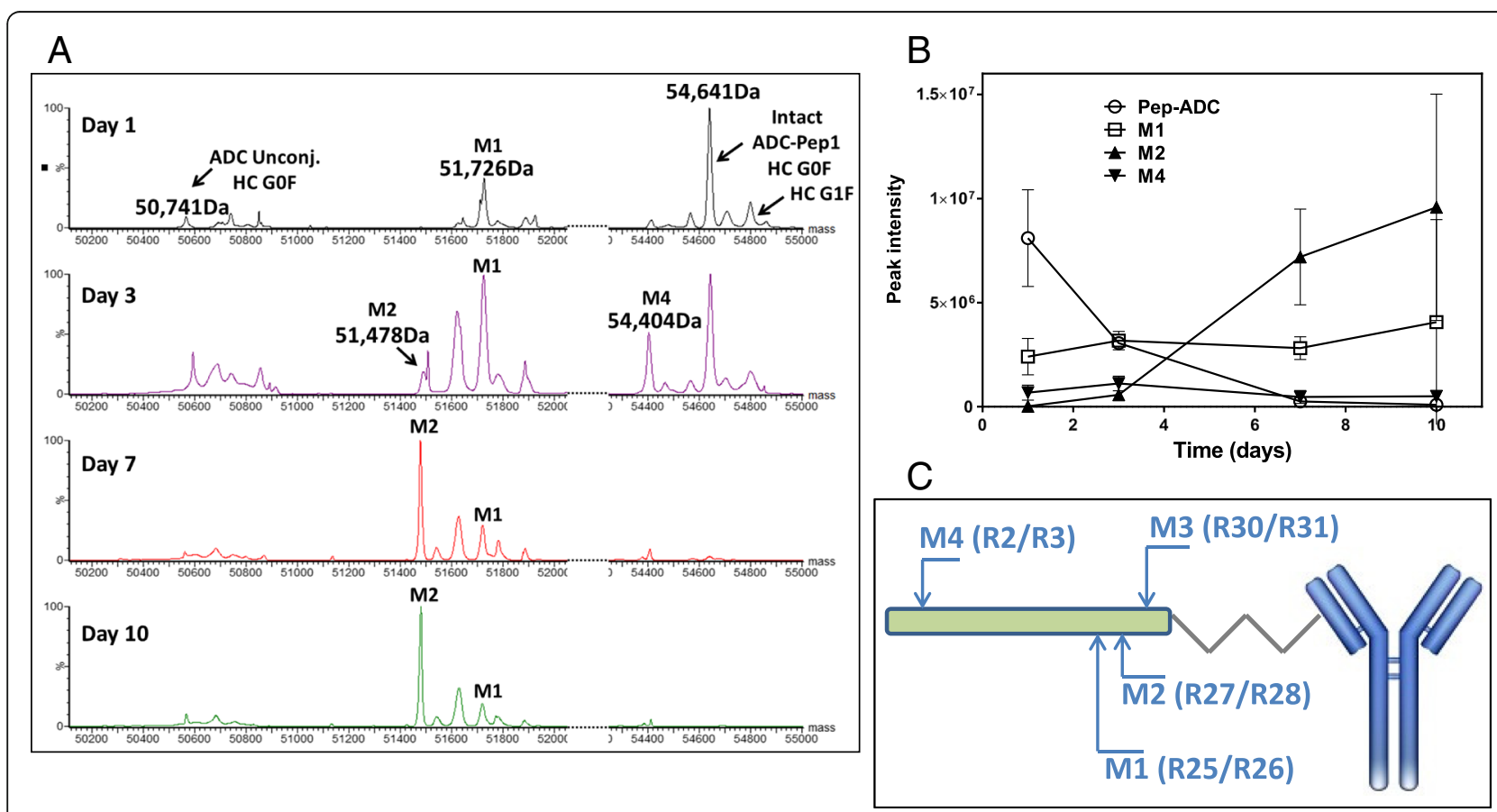

Fig. 9 Intact mass analysis of Pep-ADC in mice by AP-LC-MS. Pep-ADC (3 mg/kg) administered to C57BL/6 J diet induced obese (DIO) mice by IV was retrieved by pull-down for intact mass analysis on a Synapt G2S Q-TOF. Intact mass profiles show the appearance of several metabolites named M1, M2, and M4 (Panel a). Panel $\mathbf{b}$ shows the relative abundance of each species up to 10 days post-dosing. Data plotted are mean peak intensity from four mice per time point. Error bars correspond to the S.D. calculated using GraphPad Prism 7. Error bars shorter than the symbols are not plotted. Panel $\mathbf{c}$ indicates the sites of cleavages on the peptide that matches with metabolites 
A

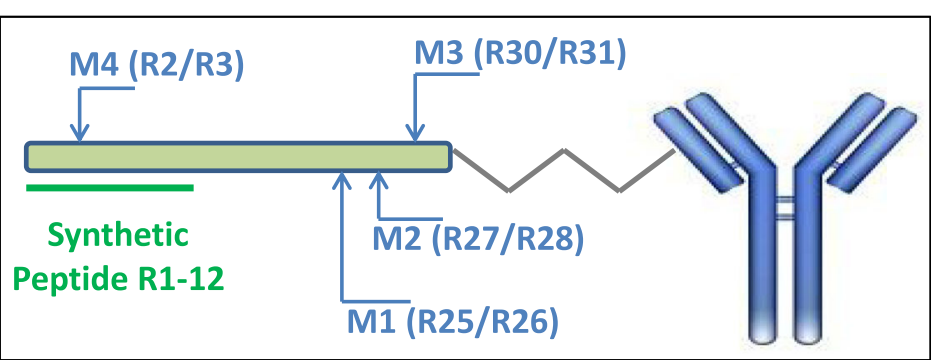

B

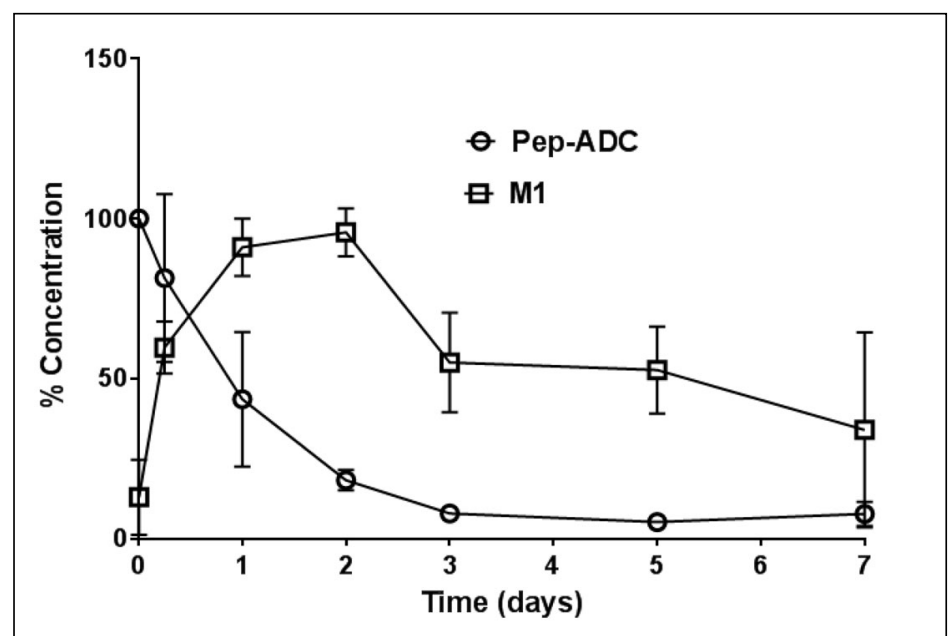

Fig. 10 Quantitative mass spectrometry based assay (LC-MRM) of intact Pep-ADC. This assay measures the concentration of the intact Pep-ADC by monitoring peptide R1-12 which covers the first 12 amino-acids of Pep-ADC (a). The relative concentration (compared to immediately after dosing) of intact Pep-ADC and main metabolite (M1) in plasma samples from C57BL/6 J normal mice IV dosed with 3 mg/kg of Pep-ADC (b). Data plotted are mean from three mice per time point (Exception: Day 3 has $n=2$ ). Error bars correspond to the S.D. calculated using GraphPad Prism 7. Error bars shorter than the symbols are not plotted

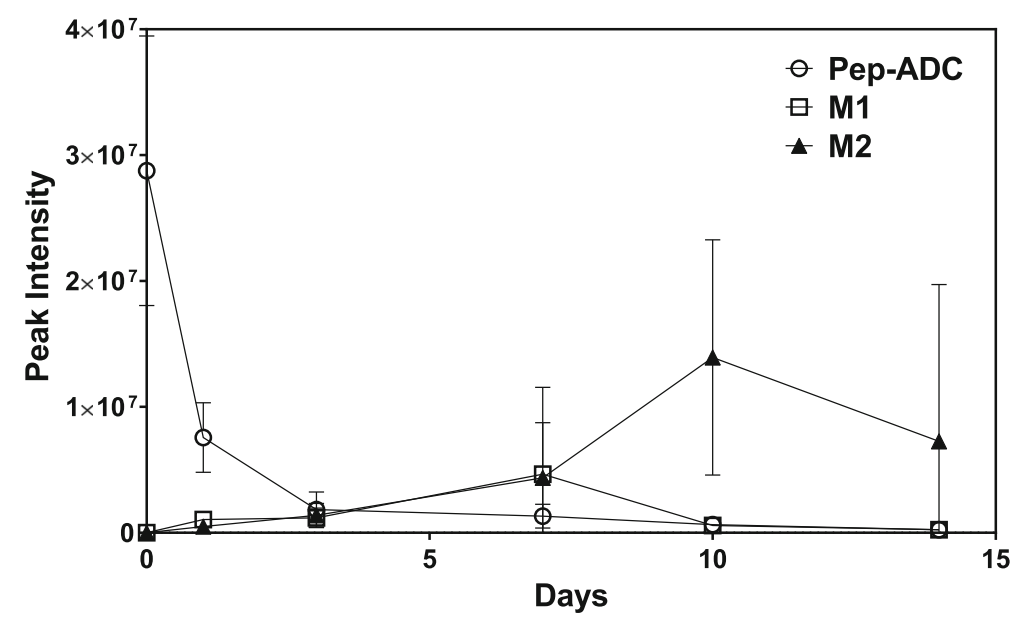

Fig. 11 Intact mass analysis of Pep-ADC by AP-LC-MS in non-human primates. Rhesus monkeys $(n=3)$ were dosed IV with a single $3 \mathrm{mg} / \mathrm{kg}$ PepADC dose. Pep-ADC in dosed plasma samples at indicated time points was retrieved by pull-down for intact mass analysis on a Synapt G2S QTOF. Relative abundance of intact Pep-ADC and main metabolites (M1 and M2) is depicted by plotting average peak intensity for up to 14 days after dosing. Data plotted are mean peak intensity from three animals per time point. Error bars correspond to the S.D. calculated using GraphPad Prism 7. Error bars shorter than the symbols are not plotted 
target mediated uptake and cellular internalization plays a more modest role (McMartin, 1992).

\section{Pep-ADC stability issue was also observed in non-human primates}

To determine whether the Pep-ADC metabolic profile observed in mice was translatable to higher order species, rhesus monkeys were administered intravenously with a single dose of Pep-ADC at $3 \mathrm{mg} / \mathrm{kg}$. Plasma was collected at $5 \mathrm{~min}$, day 1 , day 3 , day 7 , day 10 , and day 14. Intact mass analysis by AP-LC-MS showed that the intact Pep-ADC was undetectable by day 7 (Fig. 11), similar to what had been observed in mice by day 2 . Furthermore, M1 and M2 were the most abundant metabolites as early as day 3 with M1 almost completely converted to M2 by day 7. All three individual animals exhibited similar degradation profile of the Pep-ADC.

Pep-ADC exhibited normal biodisposition pattern in mice To complete the characterization of Pep-ADC in vivo and the potential role of the conjugation and the target in the tissue distribution and catabolism of this ADC, fluorophore labeled Pep-ADC and unconjugated mAb3 were intravenously administered to normal C57BL/6 J mice at $3 \mathrm{mg} / \mathrm{kg}$. Selected organs including plasma and whole blood were collected for up to 14 days after IV administration. The concentration versus time values (based on measurements of fluorescent tag on the antibody moiety) for the Pep-ADC and unconjugated mAb3 were similar, suggesting minimal effects of both the conjugation and the presence of the target in vivo at this dose (Fig. 12). The lack of noticeable gross organ uptake of both compounds was supported by the results of the tissue to blood ratios

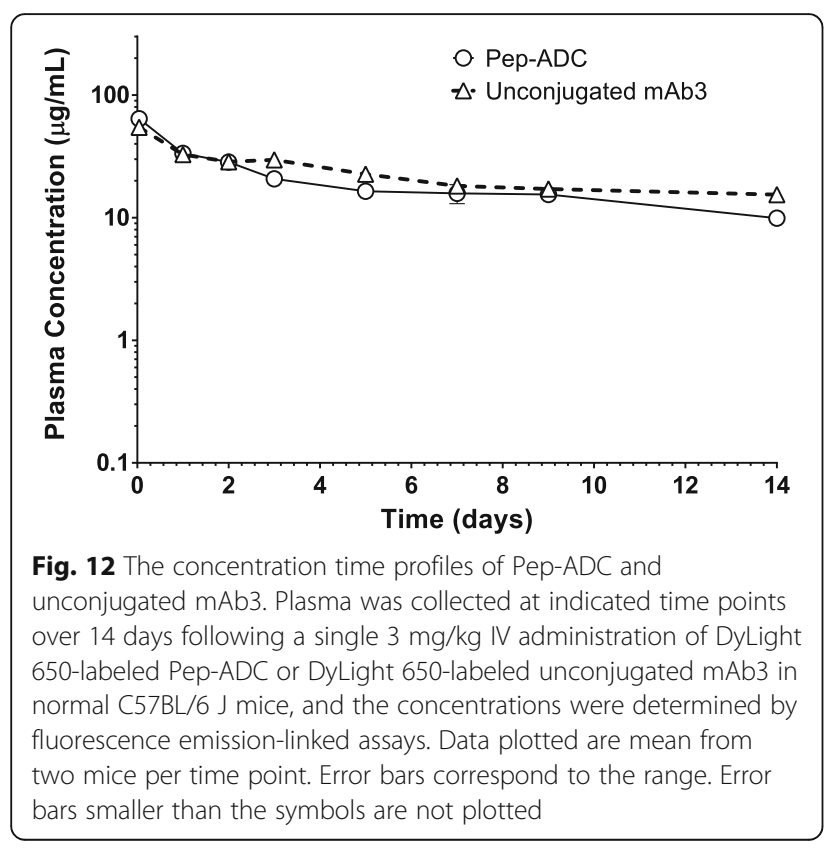

analysis, with values below 0.6 for all the organs tested over the course of the study (unpublished observations). Selected plasma samples were further characterized by SEC-HPLC. As expected, the total amount of the main monomeric peak representing intact IgG decreased with time due to antibody clearance (Fig. 13). However, SEC-HPLC profile showed that both conjugated and unconjugated constructs were stable in the circulation during this time with no evidence of formation of HMW complexes, aggregates, or major catabolic species. More than $90 \%$ of the labeled test materials remained as a single intact IgG peak by day 14 (Fig. 13). Importantly, immunohistochemical analysis clearly demonstrated that Pep-ADC but not unconjugated mAb3 efficiently localized to pancreatic Islets of Langerhans consistent with receptor mediated Pep-ADC uptake via specific peptide/receptor binding interactions (Fig. 14).

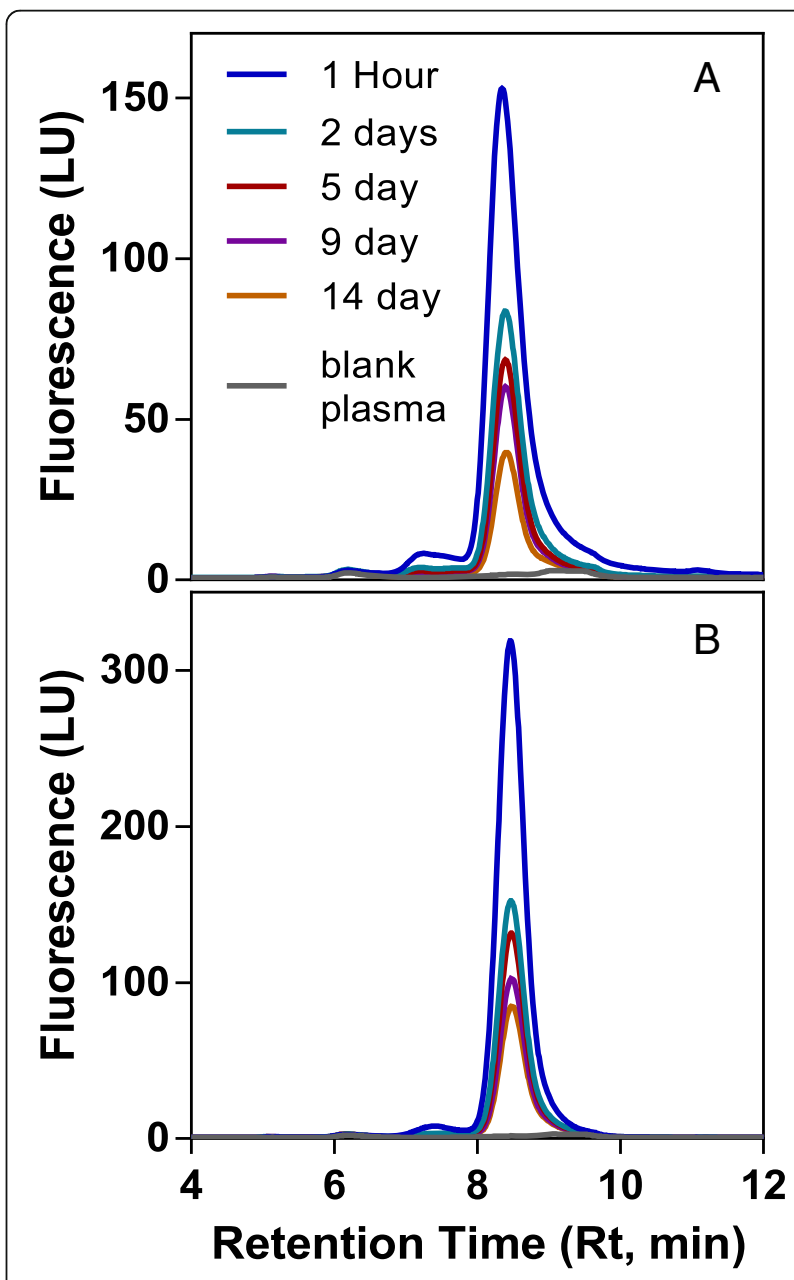

Fig. 13 In vivo stability of Pep-ADC (a) and unconjugated mAb3 (b). Shown are the fluorescence SEC-HPLC profiles of the DyLight650 labeled antibodies at indicated time points in plasma of C57BL/6 J mice after a single $3 \mathrm{mg} / \mathrm{kg}$ IV administration. The plasma samples were run on a BioSep-SEC-S3000 column at $1 \mathrm{~mL} / \mathrm{min}$ elution rate with PBS as a mobile phase for $15 \mathrm{~min}$ 


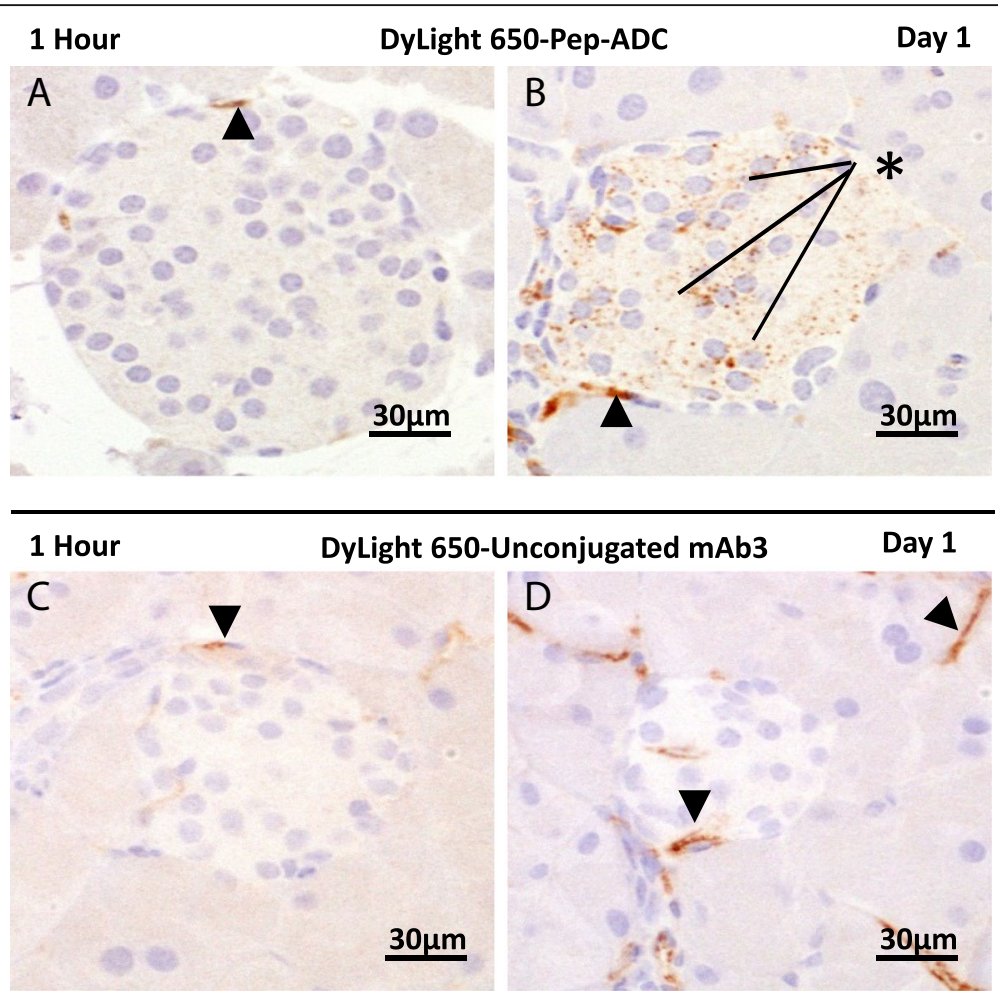

Fig. 14 Immunohistochemical analysis of cellular disposition of DyLight 650-labeled Pep-ADC (a and $\mathbf{b})$ and Dylight 650-labeled unconjugated mAb3 (c and $\mathbf{d}$ ). Tissue sections were stained with anti-DyLight 650 dye specific antibody. Asterisk $\left(^{*}\right.$ ) represents Pep-ADC localized to pancreatic Islets of Langerhans at Day 1. Arrowheads show labeling of capillaries with both antibodies

\section{Discussion}

ADCs or armed antibodies represent one of the next logical steps in the implementation of smarter, more efficient targeted drugs. Specific delivery of highly bioactive compounds to intracellular targets via antibody-receptor binding and internalization holds promise for the arrival of novel hybrid biologics with improved therapeutic windows. There are currently 2 ADCs approved in the USA (Garnock-Jones, 2013; Lambert and Chari, 2014) for oncological applications and more than 40 ADCs currently in various stages of clinical trials (Polakis, 2016; Sievers and Senter, 2013). It is recognized that there are additional challenges and complexities associated with the design and manufacturing of bio-conjugates versus standard antibodies or small molecules production. The CMC development that made possible the production of heterogeneous ADCs for successful clinical applications marks a cornerstone in biotechnology applications (Beck and Reichert, 2014). Furthermore, as improvements in the technology or novel approaches become available, we can expect additional ADCs with better overall pharmacological properties and safer profiles. The right balance needs to be engineered in the ADC so that the linker and drug are stable in blood but are promptly sorted via antibody binding and internalization to the lysosomal compartment for efficient drug release directed towards intracellular targets.

In a different modality, ADCs can also be used to exploit the excellent pharmacokinetic properties of antibodies to extend the exposure and half-life of conjugated bioactive compounds (small molecules, ligands, or peptides). It has been our experience that in general, ADME information collected from one ADC is not directly translatable to another immunoconjugate even when using the same drug-linker combination in a different antibody and against the same target. It has also been shown that even in the same ADC construct, change in drug to antibody ratios or drug load is sufficient to dramatically change the pharmacokinetic properties of the resulting conjugates (Kamath and Iyer, 2015,; Lyon et al., 2015). This is more evident when the new ADC is directed to a different target. In non-oncological applications, the need for early ADME characterization of each lead ADC-candidate is a critical step in molecule selection and rational drug design. For this purpose, the following issues need to be addressed properly: 1) Is the linker stable? 2) Is the drug stable? 3) And is the entire ADC stable? The several approaches to address these questions are also discussed in an industry white paper (Kraynov et al., 2016). 


\section{Conclusion}

In this paper, we have shown several experimental examples of two different ADC modalities (targeted internalization vs. half-life extension) and the corresponding complexities of the bioanalytical and preclinical ADME work necessary to properly characterize these entities both in vitro and in vivo. An early understanding of the critical physico-chemical components responsible for non-favorable or unexpected PK and ADME properties of experimental conjugates provides critical experimental feedback for a rational design, optimization, and selection of successful lead candidates.

\begin{abstract}
Abbreviations
(D)PBS: (Dulbecco's) Phosphate buffered saline; ADC (s): Antibody-drug conjugate (S); AP-LC-MS: Affinity purified LC-MS; $A_{U C}$ : 14: Area under the curve from zero to 14 days; $A \cup C_{0-1 N F}$ : Area under the curve from zero to infinity; Bud: Budenoside; CAMP: Cyclic adenosine monophosphate; Cat: Cathepsin based linker; $\mathrm{CH}$ 1: Heavy chain constant domain 1; $\mathrm{CHO}$ : Chinese hamster ovary; $\mathrm{CL}$ : Clearance; $C_{\max }$ : Observed maximum concentration; DAB: 3,3' Diaminobenzidine; DAR: Drug to antibody ratio; Dex: Dexamethasone; DIO: Diet induced obesity; FcRn: Neonatal Fc receptor; FELA: Fluorescence emission-linked analysis; FFPE: Formalin fixed paraffin embedded; GCGR: Glucagon receptor; GLP1R: Glucagon-like peptide 1 receptor; HMW: High molecular weight; HRP: Horseradish peroxidase; IA: Immunoassay; IACUC: Institutional animal care and use committee; IgG: Immunoglobulin; IHC: Immunohistochemistry; IL-2Ra: Interleukin-2 receptor alpha; IV: Intravenous (-ly); K2-EDTA: Ethylenediaminetetraacetic acid-dipotassium; LC-MS: Liquid chromatography-mass spectrometry; mAb (s): Monoclonal antibody (-ies); MHC: Major histocompatibility complex; Min: Minute (s); MSD: Mesoscale discovery; NCA: Non-compartmental analysis; nm: Nanometer; Pep-ADC: GLP1R/GCGR co-agonist bearing antibody drug conjugate; Phos: Phosphate based linker; PK: Pharmacokinetic; S.D.: Standard Deviation; SEC-HPLC: Size exclusion-high pressure liquid chromatography; $\mathrm{t}_{1 / 2}$ : Terminal half life; TBS: Tris buffered saline; TCEP: Tris (2carboxyethyl)phosphine; Tg: Transgenic; TMD: Target mediated disposition; Vss: Volume of distribution at steady state
\end{abstract}

\section{Acknowledgments}

The authors acknowledge the contributions of Dr. Laurence Fayadat-Dilman at the Department of Protein Sciences; Dr. Wolfgang Seghezzi at the Department of Bioanalytics; Phillip E. Brandish and Paul E. Carrington at the BiologyDiscovery Department; Robert M. Garbaccio at the Chemistry-Discovery Department; And Ambrx, Inc.

\section{Funding}

This work was supported by Merck Research Laboratories (MRL), Merck \& Co. Inc.

\section{Availability of data and materials}

The datasets supporting the conclusions of this article are included within the article.

\section{Authors' contributions}

Participated in research design: MB, GA, SZ, JHY, EE Conducted experiments: DT, DH, GE, EH, O-YS, YS, HM, SA, WM, YZ, SH, XD, ER, MJ, FV, CM. Contributed reagents: AM, NK, AB, DB, DG Performed data analysis: MB, IF, DT, DH, GE, EH, O-YS, YS, SCH, XD, ER, MJ, DN Wrote or contributed to the writing of the manuscript: MB, DN, EE. All authors read and approved the final manuscript.

\section{Competing interests}

All authors are current or former employees of Merck \& Co., Inc. or Ambrx, Inc. The authors declare no competing financial interest.

\section{Publisher's Note}

Springer Nature remains neutral with regard to jurisdictional claims in published maps and institutional affiliations.

\section{Author details}

'Bioanalytics, MRL, Merck \& Co., Inc., 901 S. California Avenue, Palo Alto, California 94304-1104, USA. ${ }^{2}$ Biologics DMPK and Disposition, MRL, Merck \& Co., Inc., 901 S. California Avenue, Palo Alto, CA 94304-1104, USA. ${ }^{3}$ Profiling and Expression Departments, MRL, Merck \& Co., Inc., 901 S. California Avenue, Palo Alto, California 94304-1104, USA. ${ }^{4}$ Ambrx, Inc., 10975 North Torrey Pines Road, La Jolla, California 92037, USA.

Received: 27 February 2018 Accepted: 10 July 2018

Published online: 08 August 2018

\section{References}

Andersen JT, Sandlie I (2009) The versatile MHC class I-related FcRn protects IgG and albumin from degradation: implications for development of new diagnostics and therapeutics. Drug metab pharmacokinet 24(4):318-332

Axup JY, Bajjuri KM, Ritland M, Hutchins BM, Kim CH, Kazane SA, Halder R, Forsyth JS, Santidrian AF, Stafin K, Lu Y, Tran H, Seller AJ, Biroc SL, Szydlik A, Pinkstaff JK, Tian F, Sinha SC, Felding-Habermann B, Smider W, Schultz PG (2012) Synthesis of site-specific antibody-drug conjugates using unnatural amino acids. Proc Natl Acad Sci U S A 109(40):16101-16106

Baumgart DC, Sandborn WJ (2007) Inflammatory bowel disease: clinical aspects and established and evolving therapies. Lancet (London, England) 369(9573): $1641-1657$

Beck A, Reichert JM (2014) Antibody-drug conjugates: present and future. mAbs 6(1):15-17

Borghese F, Clanchy FI (2011) CD74: an emerging opportunity as a therapeutic target in cancer and autoimmune disease. Expert Opin Ther Targets 15(3): 237-251

Brunn ND, Mauze S, Gu D, Wiswell D, Ueda R, Hodges D, Beebe AM, Zhang S, Escandon E (2016) The role of anti-drug antibodies in the pharmacokinetics, disposition, target engagement, and efficacy of a GITR agonist monoclonal antibody in mice. J Pharmacol Exp Ther 356(3):574-586

Brunton LL (2011) Goodman \& Gilman's the pharmacological basis of therapeutics. McGraw-Hill Education, New York

Casi G, Neri D (2012) Antibody-drug conjugates: basic concepts, examples and future perspectives. J Control Release 161(2):422-428

Day JW, Gelfanov V, Smiley D, Carrington PE, Eiermann G, Chicchi G, Erion MD, Gidda J, Thornberry NA, Tschop MH, Marsh DJ, SinhaRoy R, DiMarchi R, Pocai A (2012) Optimization of co-agonism at GLP-1 and glucagon receptors to safely maximize weight reduction in DIO-rodents. Biopolymers 98(5):443-450

Day JW, Ottaway N, Patterson JT, Gelfanov V, Smiley D, Gidda J, Findeisen H, Bruemmer D, Drucker DJ, Chaudhary N, Holland J, Hembree J, Abplanalp W, Grant E, Ruehl J, Wilson H, Kirchner H, Lockie SH, Hofmann S, Woods SC, Nogueiras R, Pfluger PT, Perez-Tilve D, DiMarchi R, Tschop MH (2009) A new glucagon and GLP-1 co-agonist eliminates obesity in rodents. Nat Chem Biol 5(10):749-757

Galaske RG, Van Liew JB, Feld LG (1979) Filtration and reabsorption of endogenous low-molecular-weight protein in the rat kidney. Kidney Int 16(3): 394-403

Garnock-Jones KP (2013) Brentuximab vedotin: a review of its use in patients with hodgkin lymphoma and systemic anaplastic large cell lymphoma following previous treatment failure. Drugs 73(4):371-381

Gorovits B, Alley SC, Bilic S, Booth B, Kaur S, Oldfield P, Purushothama S, Rao C, Shord S, Siguenza P (2013) Bioanalysis of antibody-drug conjugates: American Association of Pharmaceutical Scientists antibody-drug conjugate working group position paper. Bioanalysis 5(9):997-1006

Honey K, Forbush K, Jensen PE, Rudensky AY (2004) Effect of decreasing the affinity of the class II-associated invariant chain peptide on the MHC class II peptide repertoire in the presence or absence of $\mathrm{H}-2 \mathrm{M}$. J Immunol 172(7): $4142-4150$

Junutula JR, Flagella KM, Graham RA, Parsons KL, Ha E, Raab H, Bhakta S, Nguyen T, Dugger DL, Li G, Mai E, Lewis Phillips GD, Hiraragi H, Fuji RN, Tibbitts J, Vandlen R, Spencer SD, Scheller RH, Polakis P, Sliwkowski MX (2010) Engineered thio-trastuzumab-DM1 conjugate with an improved therapeutic index to target human epidermal growth factor receptor 2-positive breast cancer. Clin Cancer Res 16(19):4769-4778

Kamath AV, lyer S (2015) Preclinical pharmacokinetic considerations for the development of antibody drug conjugates. Pharm Res 32(11):3470-3479

Kaur S, Xu K, Saad OM, Dere RC, Carrasco-Triguero M (2013) Bioanalytical assay strategies for the development of antibody-drug conjugate biotherapeutics. Bioanalysis 5(2):201-226 
Kern JC, Cancilla M, Dooney D, Kwasnjuk K, Zhang R, Beaumont M, Figueroa I, Hsieh S, Liang L, Tomazela D, Zhang J, Brandish PE, Palmieri A, Stivers P, Cheng M, Feng G, Geda P, Shah S, Beck A, Bresson D, Firdos J, Gately D, Knudsen N, Manibusan A, Schultz PG, Sun Y, Garbaccio RM (2016a) Discovery of pyrophosphate Diesters as tunable, soluble, and bioorthogonal linkers for site-specific antibody-drug conjugates. J Am Chem Soc 138(4):1430-1445

Kern JC, Dooney D, Zhang R, Liang L, Brandish PE, Cheng M, Feng G, Beck A, Bresson D, Firdos J, Gately D, Knudsen N, Manibusan A, Sun Y, Garbaccio RM (2016b) Novel phosphate modified Cathepsin B linkers: improving aqueous solubility and enhancing payload scope of ADCs. Bioconjug Chem 27(9): 2081-2088

Knudsen LB, Pridal L (1996) Glucagon-like peptide-1-(9-36) amide is a major metabolite of glucagon-like peptide-1-(7-36) amide after in vivo administration to dogs, and it acts as an antagonist on the pancreatic receptor. Eur J Pharmacol 318(2-3):429-435

Kompella UB, Lee VHL (1991) Pharmacokinetics of peptide and protein drugs, in Peptide and Protein Drug Delivery (Lee VHL ed) Marcel Dekker, Inc., New York, pp 391-486

Kraynov E, Kamath AV, Walles M, Tarcsa E, Deslandes A, lyer RA, Datta-Mannan A, Sriraman P, Bairlein M, Yang JJ, Barfield M, Xiao G, Escandon E, Wang W, Rock DA, Chemuturi NV, Moore DJ (2016) Current approaches for absorption, distribution, metabolism, and excretion characterization of antibody-drug conjugates: an industry white paper. Drug metab dispos 44(5):617-623

Lambert JM, Chari RV (2014) Ado-trastuzumab Emtansine (T-DM1): an antibodydrug conjugate (ADC) for HER2-positive breast cancer. J Med Chem 57(16): 6949-6964

Lipworth BJ (1999) Fortnightly review: modern drug treatment of chronic asthma. BMJ 318(7180):380-384

Lyon RP, Bovee TD, Doronina SO, Burke PJ, Hunter JH, Neff-LaFord HD, Jonas M, Anderson ME, Setter JR, Senter PD (2015) Reducing hydrophobicity of homogeneous antibody-drug conjugates improves pharmacokinetics and therapeutic index. Nat Biotechnol 33(7):733-735

McGregor DP (2008) Discovering and improving novel peptide therapeutics. Curr Opin Pharmacol 8(5):616-619

McMartin C (1992) Pharmacokinetics of Peptides and Proteins: Opportunities and Challenges. In: Testa B (ed) Advances in Drug Research, pp 41-107

Nash JT, Taylor PR, Botto M, Norsworthy PJ, Davies KA, Walport MJ (2001) Immune complex processing in C1q-deficient mice. Clin Exp Immunol 123(2): 196-202

Perez HL, Cardarelli PM, Deshpande S, Gangwar S, Schroeder GM, Vite GD, Borzilleri RM (2014) Antibody-drug conjugates: current status and future directions. Drug Discov Today 19(7):869-881

Pocai A, Carrington PE, Adams JR, Wright M, Eiermann G, Zhu L, Du X, Petrov A, Lassman ME, Jiang G, Liu F, Miller C, Tota LM, Zhou G, Zhang X, Sountis MM, Santoprete A, Capito E, Chicchi GG, Thornberry N, Bianchi E, Pessi A, Marsh DJ, SinhaRoy R (2009) Glucagon-like peptide 1/glucagon receptor dual agonism reverses obesity in mice. Diabetes 58(10):2258-2266

Polakis P (2016) Antibody drug conjugates for Cancer therapy. Pharmacol Rev 68(1):3-19

Rabkin R, Dahl DC (1993) Renal uptake and disposal of proteins and peptides, in Biological Barriers to Protein Delivery (Audus KL and Raub TJ eds). Pharm Biotechnol vol 4. Springer, Boston, pp 299-338.

Rojas JR, Taylor RP, Cunningham MR, Rutkoski TJ, Vennarini J, Jang H, Graham MA, Geboes K, Rousselle SD, Wagner CL (2005) Formation, distribution, and elimination of infliximab and anti-infliximab immune complexes in cynomolgus monkeys. J Pharmacol Exp Ther 313(2):578-585

Roopenian DC, Akilesh S (2007) FcRn: the neonatal fc receptor comes of age. Nature reviews 7(9):715-725

Sato AK, Viswanathan M, Kent RB, Wood CR (2006) Therapeutic peptides: technological advances driving peptides into development. Curr Opin Biotechnol 17(6):638-642

Sievers EL, Senter PD (2013) Antibody-drug conjugates in cancer therapy. Annu Rev Med 64:15-29

Tabrizi MA, Tseng CM, Roskos LK (2006) Elimination mechanisms of therapeutic monoclonal antibodies. Drug Discov Today 11(1-2):81-88

Takai T (2002) Roles of fc receptors in autoimmunity. Nature reviews 2(8):580-592

Tian F, Lu Y, Manibusan A, Sellers A, Tran H, Sun Y, Phuong T, Barnett R, Hehli B, Song F, DeGuzman MJ, Ensari S, Pinkstaff JK, Sullivan LM, Biroc SL, Cho H, Schultz PG, DiJoseph J, Dougher M, Ma D, Dushin R, Leal M, Tchistiakova L, Feyfant E, Gerber HP, Sapra P (2014) A general approach to site-specific antibody drug conjugates. Proc Natl Acad Sci U S A 111(5):1766-1771
Triplett TA, Curti BD, Bonafede PR, Miller WL, Walker EB, Weinberg AD (2012) Defining a functionally distinct subset of human memory CD4+ T cells that are CD25POS and FOXP3NEG. Eur J Immunol 42(7):1893-1905

Wakankar A, Chen Y, Gokarn Y, Jacobson FS (2011) Analytical methods for physicochemical characterization of antibody drug conjugates. mAbs 3(2): 161-172

Zimmerman ES, Heibeck TH, Gill A, Li X, Murray CJ, Madlansacay MR, Tran C, Uter NT, Yin G, Rivers PJ, Yam AY, Wang WD, Steiner AR, Bajad SU, Penta K, Yang W, Hallam TJ, Thanos CD, Sato AK (2014) Production of site-specific antibodydrug conjugates using optimized non-natural amino acids in a cell-free expression system. Bioconjug Chem 25(2):351-361

\section{Submit your manuscript to a SpringerOpen ${ }^{\circ}$ journal and benefit from:}

- Convenient online submission

- Rigorous peer review

- Open access: articles freely available online

High visibility within the field

- Retaining the copyright to your article

Submit your next manuscript at $>$ springeropen.com 